\title{
Aircraft-based aerosol size and composition measurements during ACE-Asia using an Aerodyne aerosol mass spectrometer
}

\author{
Roya Bahreini, ${ }^{1}$ Jose L. Jimenez, ${ }^{1,2}$ Jian Wang, ${ }^{1,3}$ Richard C. Flagan, ${ }^{1}$ John H. Seinfeld, ${ }^{1}$ \\ John T. Jayne, ${ }^{4}$ and Douglas R. Worsnop ${ }^{4}$ \\ Received 26 November 2002; revised 18 February 2003; accepted 24 March 2003; published 9 August 2003
}

[1] An Aerodyne aerosol mass spectrometer (AMS) was deployed during the Aerosol Characterization Experiment-Asia (ACE-Asia) field campaign on board the Center for Interdisciplinary Remotely Piloted Aircraft Studies (CIRPAS) Twin Otter aircraft to measure the size-resolved chemical composition of submicron aerosols in the outflow from eastern Asia. Research flights were carried out from 31 March to 1 May 2001 in an area that covered $127^{\circ} \mathrm{E}-135^{\circ} \mathrm{E}$ and $32^{\circ} \mathrm{N}-38^{\circ} \mathrm{N}$. Valid data from the AMS were obtained during 15 out of a total of 19 research flights. During the mission the AMS measured distinct layers (from the boundary layer to $\sim 3700 \mathrm{~m}$ ) of submicron aerosols composed of sulfate, ammonium, and organics as the major nonrefractory components, separated by layers with much lower aerosol concentrations. Sulfate and organics mass concentrations of up to $10 \mu \mathrm{g} \mathrm{m}^{-3}$ and $13 \mu \mathrm{g} \mathrm{m}^{-3}$, respectively, were measured in some pollution layers. Back-trajectory analysis shows that the polluted layers originated in urban and industrial areas of China and Korea. The mass-weighed size distribution of the submicron sulfate was relatively constant from day to day and layer to layer, with an aerodynamic diameter mode of 400-500 nm and a width (full width half maximum) of about $450 \mathrm{~nm}$ in most of the layers. On the days with low influence of dust in the aerosol outflow, as indicated by other instruments aboard the Twin Otter, the total mass of nonrefractory aerosols estimated by the AMS correlated well with total volume of aerosols measured by a differential mobility analyzer. INDEX TERMS: 0305 Atmospheric Composition and Structure: Aerosols and particles (0345, 4801); 0345 Atmospheric Composition and Structure: Pollution - urban and regional (0305); 0365 Atmospheric Composition and Structure: Troposphere-composition and chemistry; KEYWORDS: ACE-Asia, aerosol size and composition, mass spectrometer

Citation: Bahreini, R., J. L. Jimenez, J. Wang, R. C. Flagan, J. H. Seinfeld, J. T. Jayne, and D. R. Worsnop, Aircraft-based aerosol size and composition measurements during ACE-Asia using an Aerodyne aerosol mass spectrometer, J. Geophys. Res., 108(D23), 8645, doi:10.1029/2002JD003226, 2003.

\section{Introduction}

[2] Our understanding of atmospheric aerosol properties is limited by the capabilities of instruments for ambient measurements. Although instruments capable of real-time aerosol size distribution measurements have been available for more than a decade, the ability to obtain chemical composition information with high time resolution has emerged only in the last few years [McKeown et al., 1991; Suess and Prather, 1999]. The simultaneous size and chemical compo-

\footnotetext{
${ }^{1}$ Department of Environmental Science and Engineering, California Institute of Technology, Pasadena, California, USA.

${ }^{2}$ Now at Department of Chemistry and Biochemistry, Cooperative Institute for Research in Environmental Sciences, University of Colorado, Boulder, Colorado, USA.

${ }^{3}$ Now at Environmental Science Department, Brookhaven National Laboratory, Upton, New York, USA.

${ }^{4}$ Aerodyne Research Inc., Billerica, Massachusetts, USA.

sition measurements provided by the Aerodyne aerosol mass spectrometer (AMS) make it a powerful instrument in probing aerosol properties, in real time, with high time resolution [Jayne et al., 2000; Jimenez et al., 2003b].

[3] The Aerosol Characterization Experiments (ACE), organized by the International Global Atmospheric Chemistry (IGAC) Program, have been designed to increase understanding of how aerosols affect global climate. The first Aerosol Characterization Experiment, ACE-1, was conducted during November-December 1995 over the south Pacific Ocean, south of Australia, in an attempt to quantify the chemical and physical processes that control properties of marine aerosols important for radiative forcing or climate considerations [Bates et al., 1998]. The second Aerosol Characterization Experiment, ACE-2, took place during June-July 1997 over the northeast Atlantic in order to study the properties and effects of background and anthropogenic pollution aerosols as well as dust in the marine boundary layer and free troposphere [Raes et al., 2000].

$13-1$ 
[4] The eastern Asian regional aerosol is heavily influenced by particles and particle precursors emitted by urban and industrial activities, as well as dust and biomass burning emissions. The ACE-Asia field experiment, the third in the ACE series, was carried out in eastern Asia in the spring of 2001 in order to characterize the aerosols flowing out of the east Asian continent and their evolution over the eastern Pacific Ocean, and to determine their direct effect on the radiative energy balance over the eastern Pacific region. Multiple platforms including aircraft (CIRPAS Twin Otter, NCAR C-130, and Australian King Air) and ships (NOAA R/V Ronald H. Brown, R/V Mirai, and R/V Hakuho) were deployed during ACE-Asia. Several ground-based stations (including surface sites at Kosan on Cheju Island, Korea, and in eastern China) were also instrumented to this campaign. The CIRPAS Twin Otter carried out 19 research flights from the Iwakuni Marine Corps Air Station (MCAS), Japan, during the period of 31 March to 1 May 2001. Figure 1 shows a map of the area covered as well as flight tracks of the 15 flights of the Twin Otter during which the AMS obtained valid data.

[5] The instrumentation aboard the Twin Otter was designed to measure both physical and chemical properties of the Asian aerosol, as well as to provide a set of radiation measurements to provide closure on the direct radiative effect of aerosols (in the absence of clouds). Size distribution measurements were performed using a dual differential mobility analyzer (DMA) [Wang et al., 2002], an aerodynamic particle sizer (APS 3320, TSI Inc., Minnesota), a passive cavity aerosol spectrometer probe (PCASP-100X, Particle Measurement Systems, Inc., Colorado), a cloud aerosol precipitation spectrometer (CAPS, Droplet Measurement Technologies, Colorado), a forward scattering spectrometer probe (FSSP-100, Particle Measurement Systems, Inc., Colorado), and an Aerodyne aerosol mass spectrometer (AMS). The AMS and filter samples were used to determine aerosol chemical composition. In addition, in order to obtain an estimate of the concentration of the absorbing aerosols and their light scattering properties, a particle soot absorption photometer (PSAP, Radiance Research Inc.) and a 3-color aerosol light scattering nephelometer (Model 3563, TSI Inc., Minnesota) were used. Hygroscopic aerosol behavior was evaluated using the dual dry/ambient humidity differential mobility analyzer system and a tandem differential mobility analyzer (TDMA). The optical depth of the column of air between the aircraft and the top of the atmosphere was measured with the NASA Ames 14-channel Sun photometer (AATS-14) [Schmid et al., 2003]. Downwelling and upwelling solar spectral irradiance was also measured by the NASA Ames solar spectral flux radiometer. In this paper, AMS measurements of sizeresolved chemical composition of the Asian aerosols are presented and compared with the DMA size distribution measurements as well as previous chemical composition measurements in the region.

\section{Aerodyne Aerosol Mass Spectrometer}

\subsection{Instrument Description and Specifications}

[6] An Aerodyne aerosol mass spectrometer was deployed in an airborne field study for the first time during ACE-Asia. The design of the AMS and its performance in ground-based ambient aerosol measurements have been described previously [Allan et al., 2003a, 2003b; Jayne et al., 2000; Jimenez et al., 2003b]; thus only a brief description is provided here.

[7] Figure 2 shows a schematic of the AMS. Ambient air is drawn in at a flow rate of $\sim 1.4 \mathrm{~cm}^{3} / \mathrm{s}$ through a $100 \mu \mathrm{m}$ critical orifice, and then into an aerodynamic lens based on the design of Liu et al. [1995a, 1995b] and Zhang et al. [2002]. The lens focuses the particles into a narrow beam, which then enters into a vacuum chamber while most of the gas is pumped away. Fluid dynamics simulations of the lens system as well as laboratory experiments have shown 100\% transmission efficiency of spherical particles in the range of 60-600 $\mathrm{nm}$ at sea level sampling pressure [Jayne et al., 2000]. Upon gas expansion into the vacuum chamber, the particles acquire a size-dependent terminal velocity. The particle beam is modulated by a chopper wheel that rotates at a frequency of $180 \mathrm{~Hz}$. The duty cycle of the chopper (percentage during which the chopper is open to allow for actual sampling) was 4\% during ACE-Asia. This was chosen to be larger than the typical values used $(1-2 \%)$ to increase signal-to-noise and time resolution, while sacrificing some size resolution. Particle aerodynamic size can be determined from the measured particle time of flight after calibration with particles of known sizes, densities, and shapes, such as Polystyrene Latex (PSL) spheres (Duke Scientific, Palo Alto, California).

[8] The particle beam is directed onto a resistively heated surface $\left(\sim 550^{\circ} \mathrm{C}\right)$ under high vacuum $\left(10^{-7}\right.$ Torr $)$. Upon impaction, the nonrefractory components in and on the aerosols are vaporized. These vapors are then ionized by electron impact $(70 \mathrm{eV})$, and the positive ions formed are mass analyzed with a quadrupole mass spectrometer (QMG 430, Balzers Instruments, Balzers, Liechtenstein). Because the vaporization and ionization processes are separated, particle mass can be quantified more readily. The AMS instrument with the vaporizer temperature used during ACE-Asia is not capable of detecting refractory aerosol components such as mineral dust, black carbon, or sea salt particles, although semivolatile components associated with these particles are detected.

[9] For deployments in the CIRPAS Twin Otter, the AMS is mounted on an aluminum rack of dimensions $1.05 \mathrm{~m} \times$ $1.15 \mathrm{~m} \times 0.6 \mathrm{~m}$ (picture available at http://cires.colorado. edu/jimenez/AMS_ACE_Asia.jpg). The weight of the instrument and its associated control boxes is $107 \mathrm{~kg}$, with the heaviest component being the vacuum chamber and pumps $(40.5 \mathrm{~kg})$. The rack itself weighs $\sim 20 \mathrm{~kg}$. Total power consumption of the AMS during sampling was measured to be $500 \mathrm{~W}$, with the turbo pumps consuming $210 \mathrm{~W}$.

[10] The AMS can be operated in two modes. In the TOF (time of flight) mode, size-resolved mass distributions (dM/dlog $D_{v a}$, where $D_{v a}$ is the vacuum aerodynamic diameter) of pre-selected $\mathrm{m} / \mathrm{z}$ ion signals are determined by measuring particle time of flight [Allan et al., 2003a, 2003b; Jayne et al., 2000; Jimenez et al., 2003b]. The relationship between the vacuum aerodynamic diameter and the volume-equivalent diameter $\left(D_{v}\right)$ can be expressed as [Jimenez et al., 2003a],

$$
D_{v a}=\frac{\rho_{p}}{\rho_{0}} \frac{D_{v}}{\chi_{v}}
$$




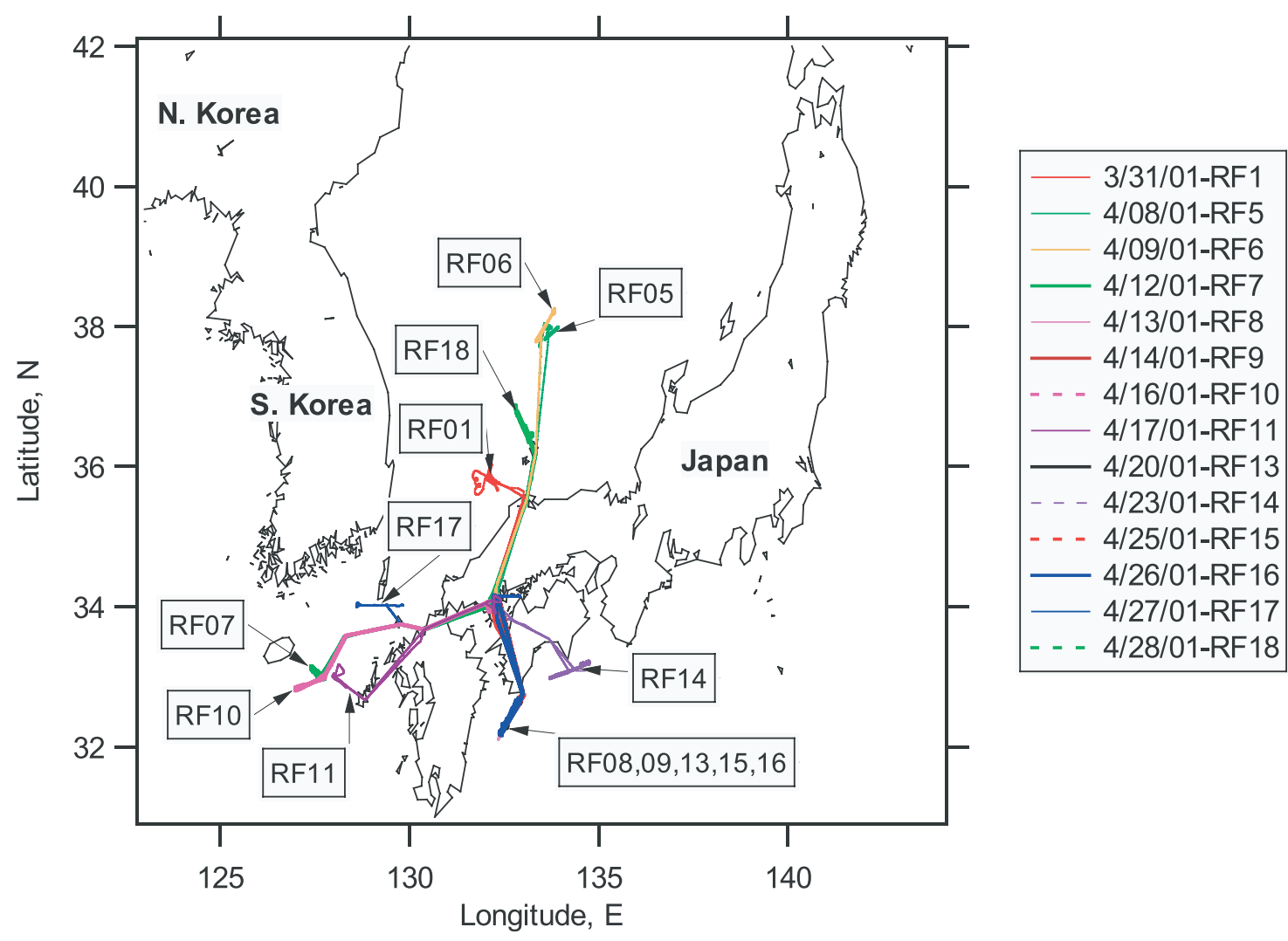

Figure 1. Twin Otter flight tracks during ACE-Asia for the flights in which the AMS obtained valid data.
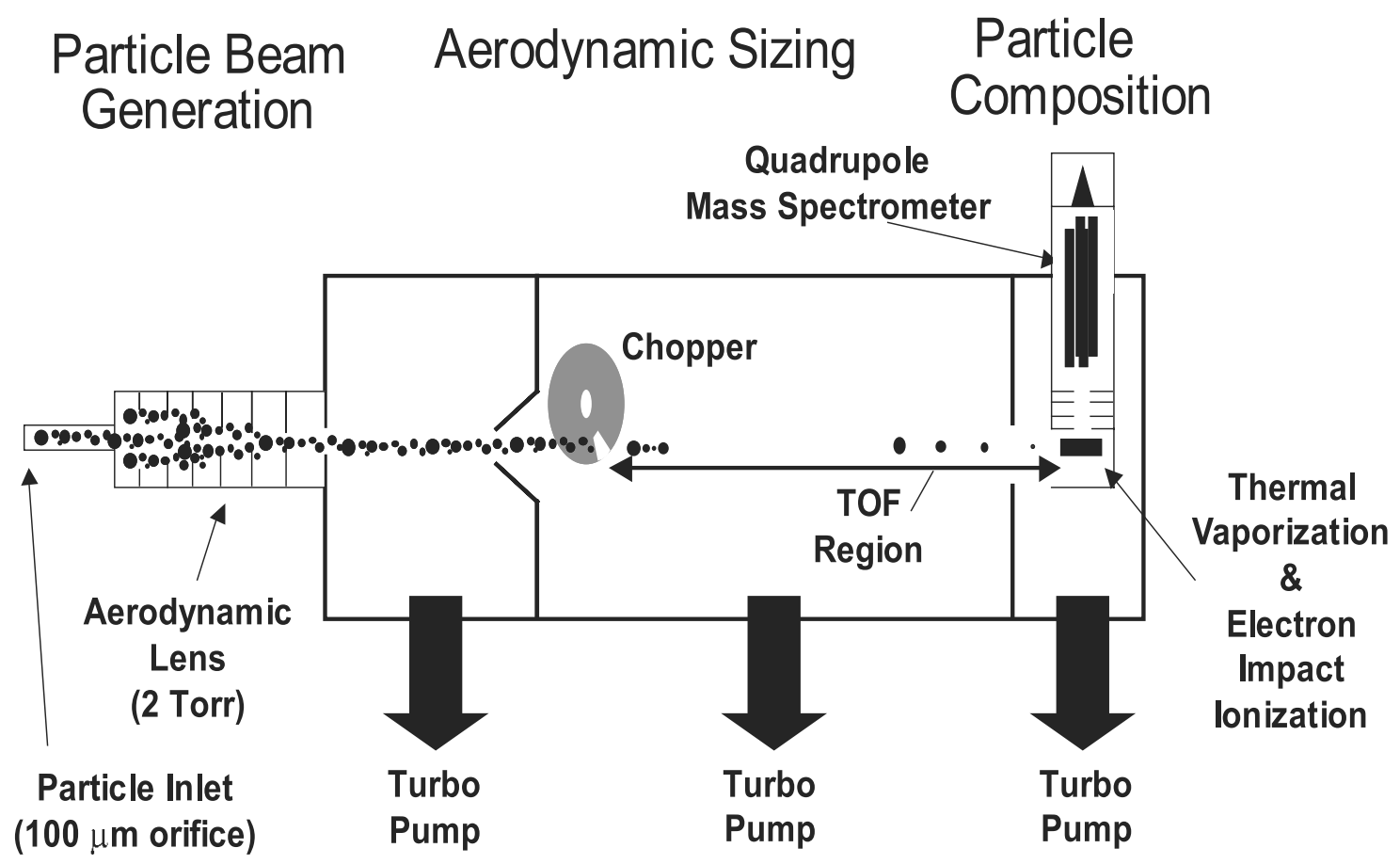

Figure 2. Schematic diagram of the Aerodyne aerosol mass spectrometer. 
Table 1. Typical Measured (1 Min) and Estimated (Longer Times) AMS Detection Limits for Sulfate, Nitrate, Ammonium, and Organics During ACE-Asia

\begin{tabular}{ccccc}
\hline & \multicolumn{4}{c}{ Detection Limits, $\mu \mathrm{g} \mathrm{m}^{-3}$} \\
\cline { 2 - 5 } Averaging Time, $\min$ & $\mathrm{SO}_{4}$ & $\mathrm{NO}_{3}$ & $\mathrm{NH}_{4}$ & Organics \\
\hline 1 & 2.39 & 3.07 & 4.35 & 11.76 \\
10 & 0.76 & 0.97 & 1.37 & 3.72 \\
60 & 0.31 & 0.40 & 0.56 & 1.52 \\
\hline
\end{tabular}

where $\rho_{p}$ is the density of the particle material, $\rho_{0}$ is unit density $\left(1 \mathrm{~g} \mathrm{~cm}^{-3}\right)$, and $\chi_{v}$ is the dynamic shape factor. In the second mode, the MS (mass spectrum) mode, mass spectra of all the nonrefractory species present in and on the aerosols are measured, without size information, for the ensemble of particles sampled.

\subsection{Fragmentation Patterns of Chemical Species in the AMS}

[11] The fragmentation patterns in the AMS for inorganic aerosol species, such as $\mathrm{NH}_{4}^{+}, \mathrm{SO}_{4}^{2-}$, and $\mathrm{NO}_{3}^{-}$, can be directly measured by sampling particles composed of pure substances in the AMS. Variation in the intensity of the signals at each fragment corresponding to a specific species can be used to determine the mass concentration of that species (section 2.3). However, special care needs to be used to detect the presence of interfering species at a given $\mathrm{m} / \mathrm{z}$. In the AMS, organic aerosol species, which fragment heavily due to the electron ionization process, could potentially interfere with the inorganic species determination. The presence of interferences can generally be detected by looking at the correlation in size and time between fragments corresponding to the same inorganic species (e.g., $\mathrm{SO}_{4}^{2-}$ ), with deviations from a linear correlation being indicative of a substantial organic interference [Jimenez et al., 2003b]. On the basis of the pure species calibration data and on the interferences detected with the above analysis, for the analysis presented here, the ammonium mass concentration is calculated using the TOF mode signal at $\mathrm{m} / \mathrm{z} 16$, which is due to $\mathrm{NH}_{2}^{+}$. Although $\mathrm{O}^{+}$and $\mathrm{O}_{2}^{++}$ions formed from the ionization of gas-phase $\mathrm{O}_{2}$ also give rise to a signal at $\mathrm{m} / \mathrm{z} 16$, the ammonium and oxygen signals can easily be separated since gas phase $\mathrm{O}_{2}$ has a much higher velocity than for any detected particles and appears early in the TOF size distributions. Other fragments of ammonium, namely $\mathrm{NH}_{4}^{+}$ ( $m / z$ 18), $\mathrm{NH}_{3}^{+}$( $\left.m / z 17\right)$, and $\mathrm{NH}^{+}(m / z 15)$, were not used in the analysis because of high background resulting from $\mathrm{H}_{2} \mathrm{O}^{+}(m / z 18)$ and $\mathrm{OH}^{+}(m / z 17)$ or low signal and interference by the $\mathrm{CH}_{3}^{+}$fragment of organics (at $\mathrm{m} / z$ 15). Sulfate mass concentration is estimated from MS mode signals of $\mathrm{SO}^{+}(m / z 48), \mathrm{SO}_{2}^{+}(m / z 64), \mathrm{SO}_{3}^{+}(m / z 80), \mathrm{HSO}_{3}^{+}(m / z 81)$, and $\mathrm{H}_{2} \mathrm{SO}_{4}^{+}(\mathrm{m} / z$ 98). Nitrate mass concentration is based on MS mode signals of $\mathrm{NO}^{+}(\mathrm{m} / \mathrm{z} 30)$ and $\mathrm{NO}_{2}^{+}(\mathrm{m} / \mathrm{z} 46)$.

[12] Organic mass concentration is estimated from major MS mode signals that are not due to air molecules, ammonium, sulfate, and nitrate. The fragmentation patterns obtained from the AMS are mostly consistent with the electron impact ionization spectra found in standard mass spectrometry libraries, such as NIST. Thus it is possible to use the relationships between organic species type (functional group presence) and characteristic peaks determined in standard EI mass spectrometry analysis to interpret the organic signals of the AMS, a method commonly referred to as "ion-series analysis" [McLafferty and Turecek, 1993]. In this analysis, organic compounds are assumed to consist of a functional group and an alkyl $\left(-\mathrm{CH}_{2}-\mathrm{CH}_{2}\right)$ chain(s). Upon electron impact ionization, the $\sigma$ bonds between the $\mathrm{C}$ atoms of the alkyl chain can be cleaved at all positions with roughly similar probabilities. That gives rise to mass spectra in which groups of peaks are separated by 14 amu units. The masses at which the peaks appear are an indication of the functional group(s) and degree of unsaturation of the molecule. A delta value $(\Delta=$ peak mass $-14 n+1$, where $n$ is the number of carbon atoms in the ion fragment) calculated for each peak mass is an indication of the functionality or unsaturation [McLafferty and Turecek, 1993]. In the ion series analysis, saturated linear or cyclic alkanes yield delta values of 0 and 2 ; unsaturated and aromatic species result in 0 or negative delta values; and oxygenated species give significant signals at delta values $\geq 2$ [McLafferty and Turecek, 1993].

\subsection{Determination of Aerosol Chemical Composition}

[13] During ACE-Asia, data were recorded every minute, with $30 \mathrm{~s}$ spent in each of the TOF mode (with $\sim 10 \mathrm{~m} / \mathrm{z}$ settings) and the MS mode (scanning $m / z$ 0-300). For either mode, the raw TOF or MS signal can be converted into mass concentration after instrument calibration during which the ionization efficiency for that species or group of species is determined [Jimenez et al., 2003b]. More specifically, in the TOF mode the raw TOF signal $(\mathrm{mV})$ of each ion, digitized at $100 \mathrm{kHz}$, is averaged and converted to ions/TOF cycle using the measured gain of

Table 2. Typical Operational Parameters Used and Examples of Particle Counting Statistics During ACE-Asia

\begin{tabular}{lc}
\hline \multicolumn{1}{c}{ Parameter } & Value \\
\hline Ambient number concentration, $\mathrm{cm}^{-3}$ & 3000 \\
Nominal flow rate, $\mathrm{cm}^{3} / \mathrm{s}$ & 1.4 \\
Number of $\mathrm{m} / \mathrm{z}$ stepped in TOF mode & 10 \\
Number of $\mathrm{m} / \mathrm{z}$ scanned in MS mode & 300 \\
Chopper duty cycle in TOF mode & 0.04 \\
Chopper duty cycle in MS mode & 0.50 \\
Duty cycle (due to peak shape) at each $\mathrm{m} / \mathrm{z}$ in MS mode & 0.40 \\
Fraction of the time in TOF (MS) mode, $\%$ & $50(50)$ \\
Data acquisition duty cycle in TOF and MS mode, $\%$ & 90 \\
Overall duty cycle for particle detection in TOF mode for a given $\mathrm{m} / \mathrm{z}, \%$ & 0.18 \\
Overall duty cycle for particle detection in MS mode for a given $\mathrm{m} / \mathrm{z}, \%$ & 0.030 \\
AMS operating time (s) needed for measuring 10 particles at a given $\mathrm{m} / \mathrm{z}$ in TOF (MS) mode & $1.3(7.9)$ \\
AMS operating time (s) needed for measuring 10 "high-mass" particles at a given $\mathrm{m} / \mathrm{z}$ in TOF (MS) mode & $66(397)$ \\
\hline
\end{tabular}




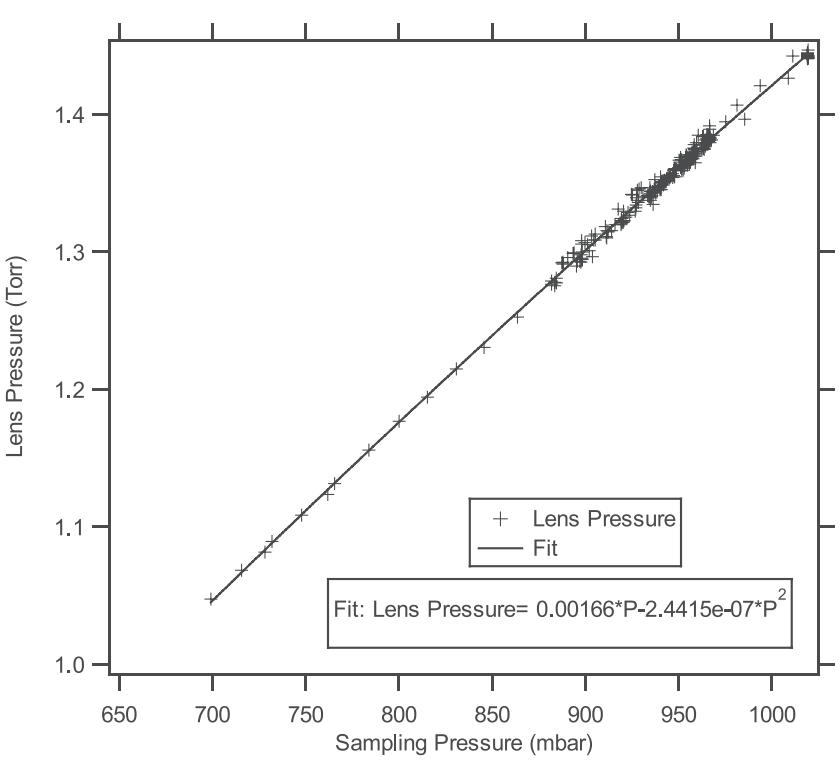

Figure 3. Variation of the pressure inside the aerodynamic lens in the AMS inlet with sampling pressure.

the electron multiplier detector and the known gain of the amplifier electronics. In order to obtain mass concentration of a species, the average ions/TOF cycle arising from different fragments of the species of interest $\left(I_{s}^{T O F}\right)$ can be converted to the species mass concentration $C_{s}\left(\mu \mathrm{g} \mathrm{m}^{-3}\right)$ as follows:

$$
C_{s}=\frac{I_{s}^{T O F}}{I E_{s}} \frac{M W_{s}}{N_{A}} \frac{f}{C Q},
$$

where $I E_{s}$ is the ionization efficiency of the species, $M W_{S}$ is the molecular weight of the species $(\mu \mathrm{g} / \mathrm{mol}), N_{A}$ is Avogadro's number, $f$ is the chopper frequency $(\mathrm{Hz}), C$ is the chopper duty cycle, and $Q$ is the sampling flow rate $\left(\mathrm{m}^{3} / \mathrm{s}\right)$.

[14] The reference species for calibration of the ionization efficiency is chosen to be ammonium nitrate because it has a simple fragmentation pattern, and it is vaporized completely under normal operating temperatures of the heater; thus it does not leave a background in the instrument. Relative calibration factors are determined in the laboratory by comparing the relative signals detected by the instrument to known mass concentrations of nitrate and the species of interest. On the basis of the observation that the ionization efficiency of a species is roughly proportional to the number of electrons in that molecule, and that the latter is linearly related to its molecular weight (for molecules with light atoms), the ionization efficiency and molecular weight of a species can be related by [Jimenez et al., 2003b]:

$$
\frac{I E_{s}}{n_{s}^{e}} \cong \frac{1}{C F_{s}^{\prime}} \frac{I E_{N O 3}}{n_{N O 3}^{e}} \Rightarrow \frac{I E_{s}}{M W_{s}} \cong \frac{1}{C F_{s}} \frac{I E_{N O 3}}{M W_{N O 3}}
$$

where $n^{e}$ is the number of electrons in the molecule of species of interest and $C F_{s}$ is the calibration factor for that species. The calibration factor also corrects for limitations on the focusing efficiency of nonspherical particles in the aerodynamic focusing inlet system, and has to be determined by comparing the mass concentration of sulfate from the AMS with another instrument. In the analysis presented here, a calibration factor of 2.5 was used for all species based on the comparison of AMS data with data from other instruments in previous field studies [Drewnick et al., 2003] (M.R. Canagaratna, Aerodyne Research, Inc., personal communication, 2002). Further experiments are underway to better estimate the calibration factor for various species.

[15] Equation (2) can be written as

$$
C_{s}=\frac{I_{s}^{T O F} C F_{s}}{I E_{N O 3}} \frac{M W_{N O 3}}{N_{A}} \frac{f}{C Q} .
$$

Similarly, the raw MS signal of different fragments of a species can be summed and converted to ions/s of that species $\left(I_{s}^{M S}\right)$, using the measured gain of the electron
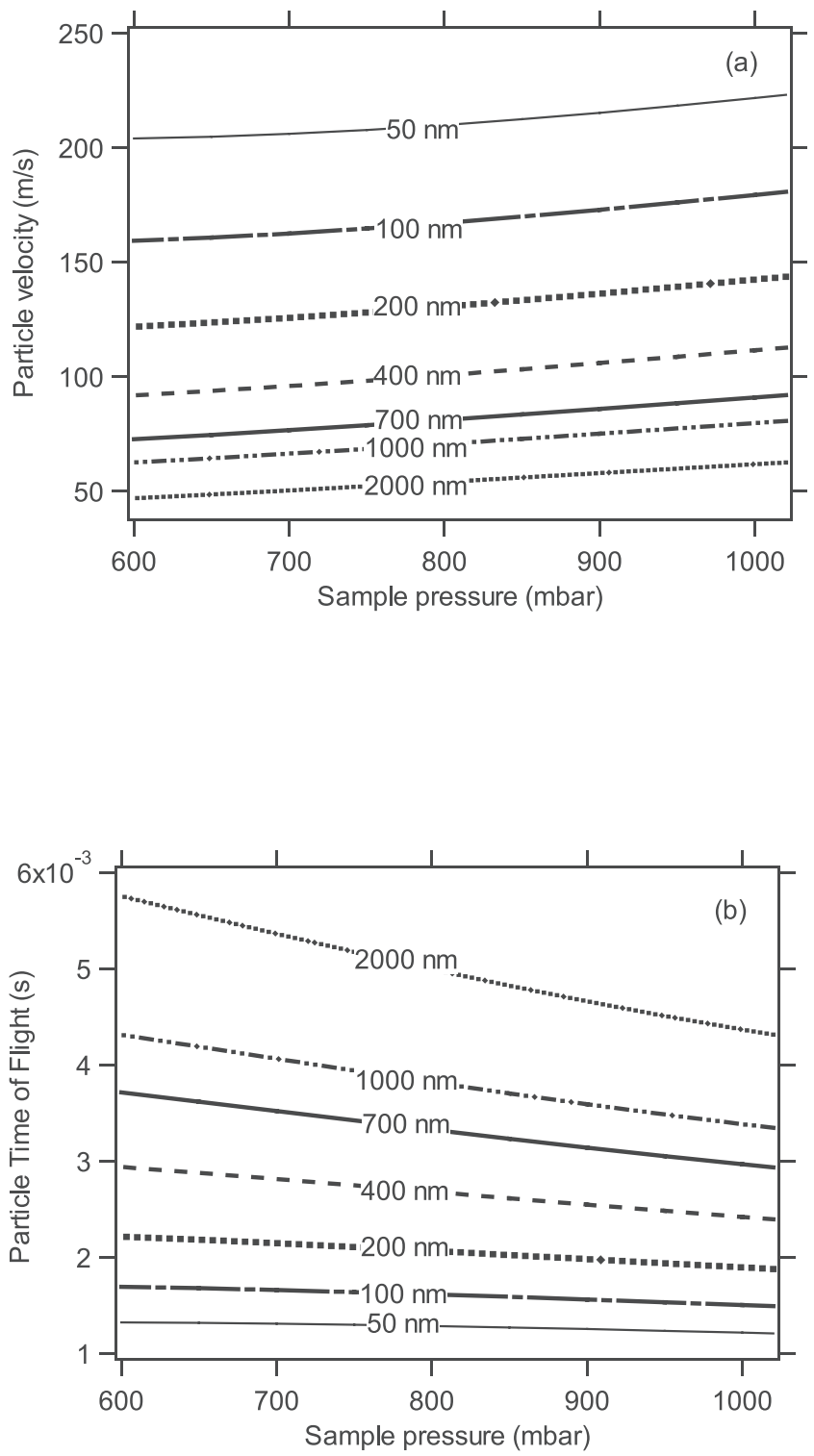

Figure 4. (a) Particle velocity and (b) time of flight variation with ambient pressure for different particle vacuum aerodynamic diameters. 


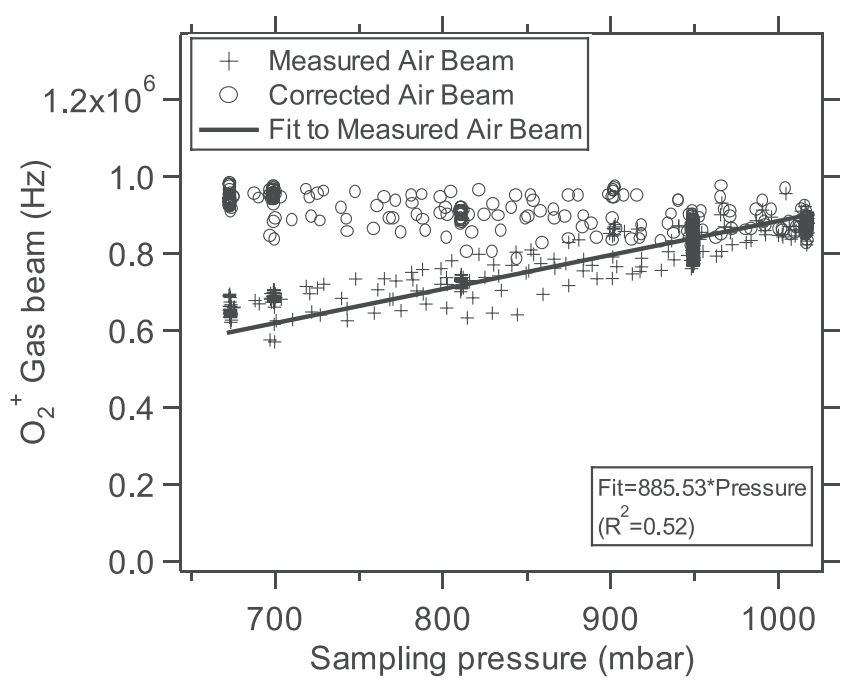

Figure 5. Variation of air beam signal intensity $(\mathrm{m} / \mathrm{z}=32$, $\mathrm{O}_{2}^{+}$) with ambient pressure.

multiplier detector and the known gain of the amplifier electronics, and then to mass concentration by

$$
C_{s}=\frac{I_{s}^{M S}}{I E_{s}} \frac{M W_{s}}{N_{A} Q}=\frac{I_{s}^{M S} C F_{S}}{I E_{N O 3}} \frac{M W_{N O 3}}{N_{A} Q} .
$$

\subsection{Detection Limits and Particle Statistics}

[16] During the ACE-Asia Twin Otter flights, TOF and MS data were recorded with 1-min time resolution, corresponding to a horizontal resolution of $\sim 3.2 \mathrm{~km}$ and a vertical resolution of $\sim 160 \mathrm{~m}$. Table 1 summarizes the estimated detection limits for sulfate, nitrate, ammonium, and organics during ACE-Asia for different averaging times. One-min detection limits were determined as three times the standard deviation of the 1-min signal in MS mode during periods with very low signal $(3 \sigma)$. Thus they should be considered an upper bound since some of the measured standard deviation may be real variations on the very low level signal. For longer averaging times, the detection limits decrease approximately proportional to $t^{-1 / 2}$. After ACE-Asia, the instrument has been upgraded, and the detection limits have improved by a factor of $\sim 20-40$ for different species.

[17] While the two modes of operating the AMS, TOF and MS, enable one to obtain both size distributions for selected $\mathrm{m} / \mathrm{z}$, and nonrefractory chemical composition of the ensemble of aerosols, the fact that there is a finite time spent at a given $\mathrm{m} / \mathrm{z}$ in each mode imposes an additional limitation on the signal-to-noise through particle counting statistics. To illustrate this effect, assume that the ambient aerosol number concentration is $3000 \mathrm{~cm}^{-3}$ (a typical measurement of the particle counters on board the Twin Otter on pollution layers during ACE-Asia). The AMS operational parameters and the results of this estimation procedure are shown in Table 2. For every minute of sampling at a typical number concentration of $3000 \mathrm{~cm}^{-3}, 252,000$ particles enter the AMS. However, the effective duty cycles for each $\mathrm{m} / \mathrm{z}$ in the TOF and MS modes are $0.18 \%$ and $0.03 \%$ respectively, so in 1 min 454 (76) particles will reach the detector for a given $\mathrm{m} / \mathrm{z}$ in TOF (MS) mode. In addition, it is typically observed that about $2 \%$ of the ambient particles contain $50 \%$ of the particle mass for a given species [Jimenez et al., 2003b]. These particles will be referred to as "high-mass particles." Since the aerosol can be heterogenous in size and composition, at least 10 particles need to be detected at each $\mathrm{m} / \mathrm{z}$ for a minimally representative statistical average of the ambient distribution. To achieve this count rate for all the particles in the TOF (MS) mode we need about 1.3 (8) seconds; however, about $66 \mathrm{~s} \mathrm{(6.6} \mathrm{min)} \mathrm{are} \mathrm{needed} \mathrm{for}$ counting 10 high-mass particles. Thus for the AMS flow rate, software control, and detection system used during ACE-Asia, a time resolution significantly smaller than 1 min was statistically unreasonable, and even with $1 \mathrm{~min}$ resolution, the high size end of the distribution will be noisy due to this effect. For this reason most of the data presented below have been averaged for uniform layers, where the consistency has been determined according to the AMS composition and size distribution, as well as size distributions and total volume distributions measured by the DMA aboard the Twin Otter.

\subsection{Variation of the AMS Size Calibration With Sampling Altitude (Pressure)}

[18] The ACE-Asia deployment was the first time in which an Aerodyne AMS had been operated on an aircraft platform. The flow into the AMS is controlled by a $100 \mu \mathrm{m}$ critical orifice which is mounted upstream of the aerodynamic lens. This aperture limits the mass flow into the lens and reduces the pressure to about 2 mbar, at which the lens has the correct particle focusing properties, when sampling from sea level pressure [Jayne et al., 2000]. Sampling at reduced pressure with the AMS, with the fixed-size critical orifice used in this study, resulted in some changes in the AMS particle size versus time of flight calibration, particle transmission versus particle size, as well as in the flow rate and the internal calibration signal ("air beam" signal). This and the next two sections address the corrections that have been applied to the AMS data to account for these effects.

[19] The vacuum aerodynamic diameter of the particles is deduced from the velocity, $v$, they acquire after expansion from the end of the aerodynamic lens ( $\sim 2$ mbar) into the vacuum chamber of the AMS. Particle time of flight, $t$, is related to the velocity by $t=L / v$, where $L$ is the distance from the chopper to the point of evaporation $(0.27 \mathrm{~m}$ for the AMS used during ACE-Asia). The relationship between particle velocity, $v$, and particle vacuum aerodynamic diameter, $D_{v a}$, can be expressed by an empirical expression in the form of

$$
v=v_{L}+\frac{v_{a}-v_{L}}{1+\left(\frac{D_{v a}}{D^{*}}\right)^{b}}
$$

where $v_{L}$ is the gas and particle velocity in the lens (determined before calibration), $v_{a}$ is the asymptotic velocity as $D_{v a}$ tends to zero (determined at calibration), and $D^{*}$ and $b$ are calibration parameters. The strength of the expansion into vacuum, and thus particle velocity varies with the lens pressure, which, in turn, depends on the sampling pressure, as shown in Figure 3. In order to account 


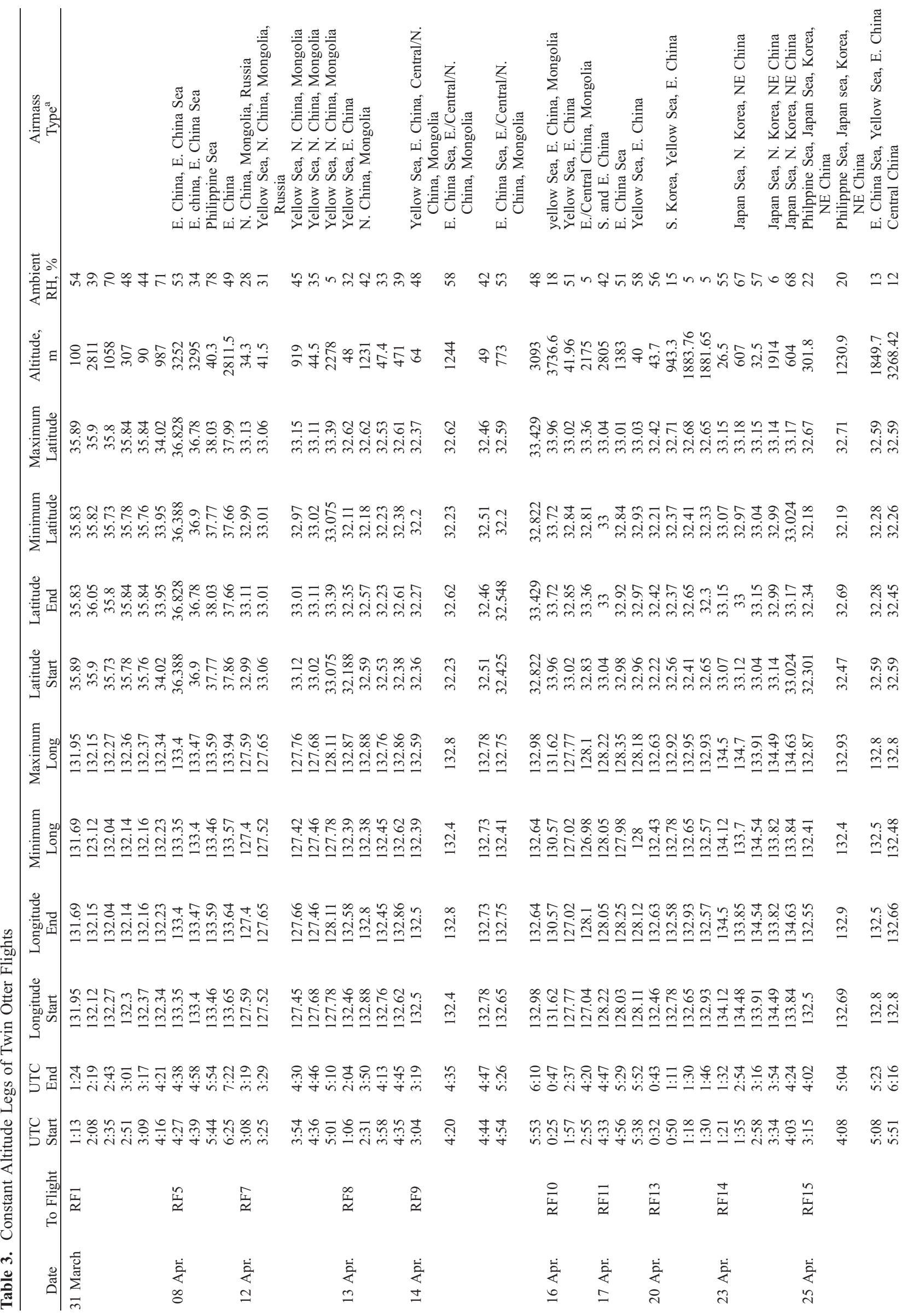




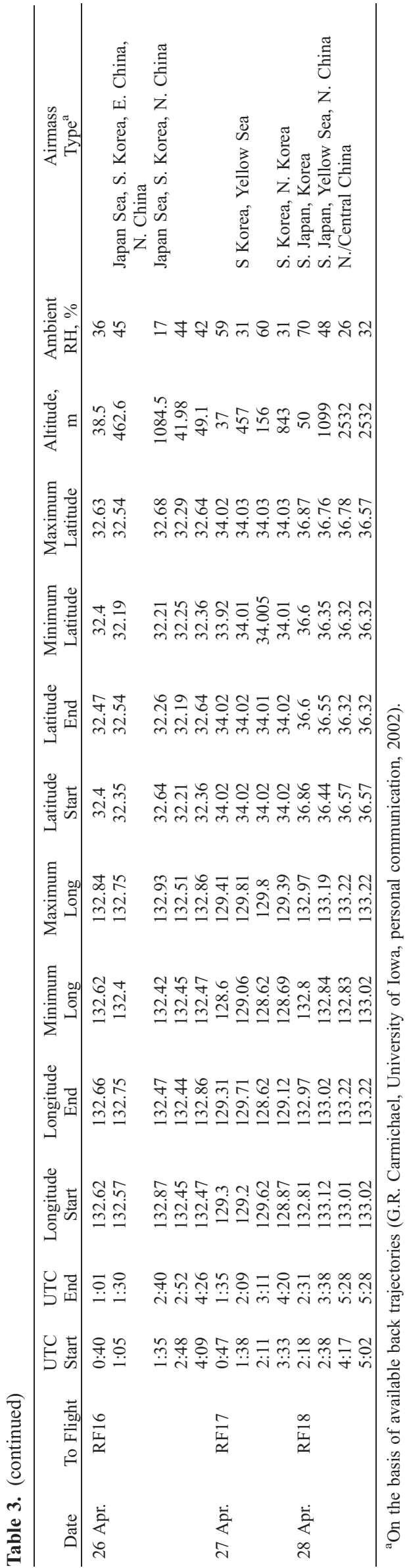

for the effect of altitude (pressure) variations during flight, a pressure-dependent size calibration was determined from laboratory experiments in which calibration particles of precisely known size, density, and shape (PSLs, Polystyrene Latex Spheres, from Duke Scientific, Palo Alto, California, from $100 \mathrm{~nm}$ to $900 \mathrm{~nm}$, with coefficient of variation of $1.0 \%-7.5 \%)$ were introduced into the AMS. The inlet pressure was reduced from ambient sea level ( $\sim 1012$ mbar $)$ to $620 \mathrm{mbar}$, corresponding to that at an altitude of $\sim 4000 \mathrm{~m}$, and controlled by a needle valve and an additional pump upstream of the AMS inlet. The calibration parameters were derived for four different pressures, and the results for each parameter were fit to an appropriate functional form in order to produce a self-consistent set of calibration parameters. The following equations summarize the results and the estimate of uncertainties (one standard deviation is indicated in parenthesis) of how the parameters of equation (6) vary with sampling pressure $(P$, mbar):

$$
\begin{gathered}
v_{a}=614( \pm 10)-0.0309( \pm 0.0117) P \\
v_{L}=4.45( \pm 0.69)+0.00581( \pm 0.00083) P \\
D^{*}=24.8( \pm 0.6)-0.0342( \pm 0.0016) P+2.59 \cdot 10^{-5} \\
\quad \cdot\left( \pm 9.73 \cdot 10^{-7}\right) P^{2} \\
b=0.702( \pm 0.070)-3.89 \cdot 10^{-4}\left( \pm 1.76 \cdot 10^{-4}\right) P+1.69 \cdot 10^{-7} \\
\cdot\left( \pm 1.08 \cdot 10^{-7}\right) P^{2} .
\end{gathered}
$$

With the lens system of the AMS during ACE-Asia, parameters $v_{L}$ and $D^{*}$ are the most sensitive with respect to changes in pressure (both change $\sim 20 \%$ with $40 \%$ pressure change) and $v_{a}$ is the least sensitive (changes $\sim 3 \%$ with $40 \%$ pressure change). In terms of the effect on particle velocity, parameter $b\left(D^{*}\right)$ has the most effect for particles with vacuum aerodynamic diameter greater (less) than $150 \mathrm{~nm}$. On the other hand, parameter $v_{a}\left(v_{l}\right)$ has the least effect for particles with vacuum aerodynamic diameter greater (less) than $\sim 520 \mathrm{~nm}$.

[20] Figure 4 shows how the velocity and the particle time of flight vary with changing sampling pressure. A $700 \mathrm{~nm}$ particle sampled at ambient pressure has the same terminal velocity as a $400 \mathrm{~nm}$ particle if sampled at 600 mbar. This correction can still be significant (up to $\sim 7 \%$ ) for weatherinduced pressure changes at a fixed location on the Earth's surface or when the instrument is moved to a new surface location at a different altitude.

[21] The transmission efficiency (percentage of sampled particles at a given size reaching the AMS detector) is also expected to change at lower sampling pressures. Fluid dynamics simulations of the aerodynamic lens indicate that the high transmission efficiency region may shift slightly for the smaller sizes at lower pressure (X. Zhang, Aerodyne Research Inc., personal communication, 2002). For example, the transmission efficiency of $30 \mathrm{~nm}(20 \mathrm{~nm})$ particles improves from $75 \%(15 \%)$ to $100 \%$ (45\%) by reducing the sampling pressure from 950 mbar to 480 mbar. Additional experiments required to directly characterize this effect are underway. However, in this study we have attempted to bound the importance of this issue by comparing the particle concentrations determined by the AMS and by the DMA 
Table 4. AMS Averaged Mass Concentration Data ( $\mu \mathrm{g} \mathrm{m}^{-3}$ at STP) and Standard Deviations (STD, $\mu \mathrm{g} \mathrm{m}^{-3}$ at STP) of Sulfate, Nitrate, and Ammonium During Constant-Altitude Legs ${ }^{\mathrm{a}}$

\begin{tabular}{|c|c|c|c|c|c|c|c|c|c|c|c|}
\hline Date & To Flight & UTC Start & UTC End & [SO4] & STD [SO4] & [NO3] & STD [NO3] & [Org] & STD [Org] & [NH4] & STD [NH4] \\
\hline \multirow[t]{6}{*}{31 March } & RF1 & $1: 13$ & $1: 24$ & 0.14 & 0.4 & 0.13 & 0.68 & 0.57 & 0.99 & & \\
\hline & & 2:08 & $2: 19$ & 0.064 & 0.095 & & & & & & \\
\hline & & $2: 35$ & $2: 43$ & 0.15 & 0.11 & & & 0.08 & 0.51 & & \\
\hline & & $2: 51$ & 3:01 & 0.13 & 0.1 & 0.04 & 0.32 & & 0 & & \\
\hline & & 3:09 & $3: 17$ & 0.16 & 0.055 & 0.04 & 0.29 & 0.3 & 0.58 & & \\
\hline & & $4: 16$ & $4: 21$ & 0.21 & 0.09 & 0.12 & 0.23 & 0.089 & 0.32 & & \\
\hline \multirow[t]{4}{*}{8 April } & RF5 & $4: 27$ & $4: 38$ & 1.4 & 0.55 & & & 0.82 & 2.28 & & \\
\hline & & $4: 39$ & $4: 58$ & 1.16 & 0.67 & 0.01 & 0.84 & 1.12 & 1.8 & & \\
\hline & & $5: 44$ & $5: 54$ & 1.09 & 0.14 & 0.28 & 0.38 & 2.24 & 1.2 & & \\
\hline & & $6: 25$ & $7: 22$ & 1.07 & 0.52 & & & 1.12 & 1.42 & & \\
\hline \multirow[t]{5}{*}{12 April } & RF7 & 3:08 & $3: 19$ & 4.02 & 1.38 & 1.09 & 2.8 & 5.86 & 12.64 & & \\
\hline & & $3: 25$ & $3: 29$ & 4.42 & 1.29 & 2.58 & 5.16 & 4.57 & 12.18 & & \\
\hline & & $3: 54$ & $4: 30$ & 4.97 & 2.09 & 1.66 & 3.94 & 4.25 & 8.9 & & \\
\hline & & $4: 36$ & $4: 46$ & 5.29 & 2.3 & 2.72 & 3 & 4.31 & 9.18 & & \\
\hline & & 5:01 & $5: 10$ & 3 & 2.17 & & & 3.67 & 11.93 & & \\
\hline \multirow[t]{4}{*}{13 April } & RF8 & 1:06 & 2:04 & 2.82 & 1.42 & 1.07 & 4.15 & 2.03 & 4.45 & 1.64 & 3.92 \\
\hline & & $2: 31$ & $3: 50$ & 2.61 & 1.10 & 0.98 & 1.27 & 2.28 & 3.86 & 1.31 & 3.17 \\
\hline & & $3: 58$ & $4: 13$ & 3.34 & 0.95 & 0.62 & 0.89 & 0.67 & 3.51 & 0.72 & 3.93 \\
\hline & & $4: 35$ & $4: 45$ & 3.98 & 2.72 & 0.74 & 0.95 & 3.21 & 4.72 & 1.63 & 3.95 \\
\hline \multirow[t]{5}{*}{14 April } & RF9 & $3: 04$ & $3: 19$ & 7.03 & 1.2 & 0.68 & 1.58 & 3.11 & 5.19 & 1.72 & 2.86 \\
\hline & & $4: 20$ & $4: 35$ & 5.18 & 1.65 & 0.74 & 2 & 4.16 & 5.64 & 2.15 & 2.07 \\
\hline & & $4: 44$ & $4: 47$ & 4.65 & 1.1 & 1.64 & 1.99 & 4.46 & 2.33 & 0.32 & 1.98 \\
\hline & & $4: 54$ & $5: 26$ & 5.51 & 1.23 & 0.95 & 2.06 & 1.91 & 3.43 & 1.61 & 2.3 \\
\hline & & $5: 53$ & $6: 10$ & 3.29 & 2.31 & 0.41 & 2.49 & 2.55 & 5.67 & & \\
\hline \multirow[t]{3}{*}{16 April } & RF10 & $0: 25$ & $0: 47$ & 0.52 & 0.29 & & & 0.11 & 2.83 & 3.38 & 3.29 \\
\hline & & $1: 57$ & $2: 37$ & 0.31 & 0.16 & 0.019 & 0.082 & 0.046 & 1.98 & 1.29 & 1.86 \\
\hline & & $2: 55$ & $4: 20$ & 0.21 & 0.16 & 0.014 & 0.13 & 0.2 & 2.7 & 0.97 & 1.91 \\
\hline \multirow[t]{3}{*}{17 April } & RF11 & $4: 33$ & $4: 47$ & 2.36 & 2.28 & 0.48 & 2.19 & & & 2.99 & 3.2 \\
\hline & & $4: 56$ & $5: 29$ & 10.31 & 3.51 & 1.45 & 1.95 & 3.65 & 7.33 & 4.14 & 2.81 \\
\hline & & $5: 38$ & $5: 52$ & 5.52 & 2.06 & 0.8 & 2.2 & 1.71 & 5.2 & 1.35 & 1.79 \\
\hline \multirow[t]{4}{*}{20 April } & RF13 & $0: 32$ & $0: 43$ & 5.26 & 2.04 & 0.75 & 0.54 & 2.89 & 4.48 & 1.41 & 0.69 \\
\hline & & $0: 50$ & $1: 11$ & 1.43 & 0.78 & 0.66 & 1.08 & 3.41 & 4.83 & 0.76 & 0.99 \\
\hline & & $1: 18$ & $1: 30$ & 0.73 & 0.94 & & & 1.65 & 4.66 & 1.09 & 0.82 \\
\hline & & $1: 30$ & $1: 46$ & 0.78 & 1.1 & 0.3 & 1.15 & 0.91 & 4.55 & 0.97 & 1.05 \\
\hline \multirow[t]{5}{*}{23 April } & RF14 & $1: 21$ & $1: 32$ & 2.4 & 1.11 & 0.35 & 2.16 & 4.36 & 8.82 & 1.31 & 1.87 \\
\hline & & $1: 35$ & $2: 54$ & 2.72 & 1.34 & 0.96 & 1.92 & 5.08 & 7.45 & 0.98 & 1.83 \\
\hline & & $2: 58$ & $3: 16$ & 2.58 & 0.82 & 0.83 & 2.19 & 5.1 & 6.38 & 1.63 & 1.45 \\
\hline & & $3: 34$ & $3: 54$ & 1.29 & 1.04 & & & & & & \\
\hline & & 4:03 & $4: 24$ & 3.09 & 1.07 & 1.08 & 1.68 & 8.19 & 7.5 & 1.6 & 2.9 \\
\hline \multirow[t]{4}{*}{25 April } & RF15 & $3: 15$ & 4:02 & 0.97 & 1.32 & 0.17 & 1.7 & 3.02 & 6.01 & 0.33 & 2.56 \\
\hline & & 4:08 & $5: 04$ & 1.3 & 1.09 & 0.14 & 1.66 & 2.92 & 5.92 & 0.59 & 2.34 \\
\hline & & $5: 08$ & $5: 23$ & & & & & 1.55 & 6.36 & & \\
\hline & & $5: 51$ & $6: 16$ & 0.7 & 1.02 & & & 5.97 & 6.32 & & \\
\hline \multirow[t]{5}{*}{26 April } & RF16 & $0: 40$ & $1: 01$ & 1.11 & 0.83 & 0.39 & 0.72 & 4.03 & 3.26 & 1.3 & 2.41 \\
\hline & & $1: 05$ & $1: 30$ & 0.85 & 0.66 & 0.4 & 0.89 & 3.65 & 2.49 & 0.3 & 1.94 \\
\hline & & $1: 35$ & $2: 40$ & 0.76 & 0.52 & 0.28 & 0.65 & 4.22 & 2.43 & 0.22 & 2.02 \\
\hline & & $2: 48$ & $2: 52$ & 0.72 & 0.59 & 0.77 & 0.56 & 4.93 & 2.61 & & \\
\hline & & 4:09 & $4: 26$ & 0.97 & 0.67 & 0.45 & 0.89 & 2.72 & 3.39 & 0.039 & 2.4 \\
\hline \multirow[t]{4}{*}{27 April } & RF17 & $0: 47$ & $1: 35$ & 4.27 & 1.18 & 1.33 & 1.6 & 10.86 & 5.25 & 0.67 & 1.25 \\
\hline & & $1: 38$ & 2:09 & 2.53 & 1.19 & 1.44 & 1.87 & 12.73 & 4.7 & 0.82 & 0.94 \\
\hline & & $2: 11$ & $3: 11$ & 3.72 & 1.19 & 2.27 & 6.8 & 11.22 & 4.66 & 0.52 & 1.29 \\
\hline & & $3: 33$ & $4: 20$ & 2.21 & 1.25 & 1.14 & 1.4 & 10 & 5.86 & 0.57 & 1.42 \\
\hline \multirow[t]{4}{*}{28 April } & RF18 & $2: 18$ & $2: 31$ & 4.04 & 1.47 & 0.39 & 1.58 & 9.47 & 4.66 & 1.5 & 1.51 \\
\hline & & $2: 38$ & $3: 38$ & 5.67 & 1.83 & 0.61 & 1.14 & 9.47 & 5.11 & 1.45 & 1.28 \\
\hline & & $4: 17$ & $5: 28$ & 1.76 & 1.44 & 0.06 & 1.01 & 1.33 & 6.37 & 0.02 & 1.64 \\
\hline & & 5:02 & $5: 28$ & 2.35 & 1.21 & & & 1.84 & 5.39 & & \\
\hline
\end{tabular}

${ }^{\mathrm{a}}$ Average values above the detection limit of each leg are indicated in bold.

system, also operated in the Twin Otter, as a function of altitude [Wang et al., 2002] (section 4.).

\subsection{Variation of the AMS Sample Flow Rate Measurement With Altitude}

[22] In this section, the expected flow variation with sampling altitude and the systematic deviations that can be expected on the particular flow measurement device (laminar flowmeter) and for the AMS inlet system (fixed size critical orifice) used here as a function of altitude are described. The volumetric flow rate $(Q)$ through a critical orifice can be expressed as a function of discharge coefficient $\left(k_{d}\right)$, cross-sectional area of the orifice $(A)$, density of air $(\rho)$, specific heat ratio of air $(\gamma)$, and upstream pressure $(P)$ [Willeke and Baron, 1993]:

$$
Q=0.58 k_{d} A \sqrt{\left(\frac{\gamma P}{\rho}\right)} .
$$


Table 5. AMS Sulfate, Organics, Nitrate, and Ammonium Mass Distribution Vacuum Aerodynamic Mode Diameter (nm) and Full Width Half Maximum (FWHM, nm) Measured During Constant-Altitude Legs

\begin{tabular}{|c|c|c|c|c|c|c|c|c|c|c|c|}
\hline Date & $\begin{array}{c}\text { TO } \\
\text { Flight }\end{array}$ & $\begin{array}{l}\text { UTC } \\
\text { Start }\end{array}$ & $\begin{array}{l}\text { UTC } \\
\text { End }\end{array}$ & Mode_SO4 & FWHM_SO4 & Mode_Org & FWHM_Org & Mode_NO3 & FWHM_NO3 & Mode_NH4 & FWHM_NH4 \\
\hline \multirow{6}{*}{31 March } & RF1 & $1: 13$ & $1: 24$ & & & & & & & & \\
\hline & & 2:08 & $2: 19$ & & & & & & & & \\
\hline & & $2: 35$ & $2: 43$ & & & & & & & & \\
\hline & & $2: 51$ & 3:01 & & & & & & & & \\
\hline & & 3:09 & $3: 17$ & & & & & & & & \\
\hline & & $4: 16$ & $4: 21$ & & & & & & & & \\
\hline \multirow[t]{4}{*}{8 April } & RF5 & $4: 27$ & $4: 38$ & 465 & 345 & & & & & & \\
\hline & & $4: 39$ & $4: 58$ & 463 & 311 & & & & & & \\
\hline & & $5: 44$ & $5: 54$ & 430 & 445 & 288,590 & 111,427 & & & & \\
\hline & & $6: 25$ & $7: 22$ & 452 & 377 & & & & & & \\
\hline \multirow[t]{5}{*}{12 April } & RF7 & $3: 08$ & $3: 19$ & 455 & 457 & & & & & & \\
\hline & & $3: 25$ & $3: 29$ & 390 & 615 & & & & & & \\
\hline & & $3: 54$ & $4: 30$ & 394 & 474 & & & & & & \\
\hline & & $4: 36$ & $4: 46$ & 425 & 474 & & & & & & \\
\hline & & $5: 01$ & $5: 10$ & 415 & 368 & 1298 & 916 & & & & \\
\hline \multirow{4}{*}{13 April } & RF8 & 1:06 & $2: 04$ & 403 & 558 & 173,627 & 223,596 & 187,915 & $1,851,290$ & 389 & 800 \\
\hline & & $2: 31$ & $3: 50$ & 393 & 547 & 621 & 535 & 381 & 592 & 291 & 736 \\
\hline & & $3: 58$ & $4: 13$ & 349 & 587 & & & & & & \\
\hline & & $4: 35$ & $4: 45$ & 376 & 463 & & & & & 444 & 774 \\
\hline \multirow[t]{5}{*}{14 April } & RF9 & $3: 04$ & $3: 19$ & 415 & 456 & & & & & 387 & 820 \\
\hline & & $4: 20$ & $4: 35$ & 390 & 320 & & & & & 310,1006 & 556,668 \\
\hline & & $4: 44$ & $4: 47$ & 400 & 354 & & & & & & \\
\hline & & $4: 54$ & $5: 26$ & 380 & 360 & & & & & & \\
\hline & & $5: 53$ & $6: 10$ & & & & & & & & \\
\hline \multirow[t]{3}{*}{16 April } & RF10 & $0: 25$ & $0: 47$ & 399 & 270 & 115 & 203 & & & & \\
\hline & & $1: 57$ & $2: 37$ & 428 & 508 & & & & & 413 & 621 \\
\hline & & $2: 55$ & $4: 20$ & 412 & 399 & & & & & 377 & 689 \\
\hline \multirow[t]{3}{*}{17 April } & RF11 & $4: 33$ & $4: 47$ & 406 & 326 & & & & & & \\
\hline & & $4: 56$ & $5: 29$ & 460 & 380 & 170,384 & 69,270 & & & 384 & 950 \\
\hline & & $5: 38$ & $5: 52$ & 415 & 434 & & & & & 387 & 800 \\
\hline \multirow[t]{4}{*}{20 April } & RF13 & $0: 32$ & $0: 43$ & 536 & 635 & 253 & 289 & & & 185,552 & 151,538 \\
\hline & & $0: 50$ & $1: 11$ & 480 & 776 & & & & & & \\
\hline & & $1: 18$ & $1: 30$ & 552 & 617 & 393 & 462 & & & & \\
\hline & & $1: 30$ & $1: 46$ & 552 & 617 & & & & & & \\
\hline \multirow[t]{5}{*}{23 April } & RF14 & $1: 21$ & $1: 32$ & 433 & 385 & & & 162 & 153 & 407 & 468 \\
\hline & & $1: 35$ & $2: 54$ & 420 & 484 & 448 & 530 & & & 433,485 & 485,267 \\
\hline & & $2: 58$ & $3: 16$ & 404 & 580 & & & & & 648 & 1105 \\
\hline & & $3: 34$ & $3: 54$ & 430 & 311 & & & & & & \\
\hline & & $4: 03$ & $4: 24$ & 420 & 482 & 320,869 & 375,435 & 164,604 & 191,462 & 297,869 & 285,368 \\
\hline \multirow[t]{4}{*}{25 April } & RF15 & $3: 15$ & 4:02 & 456 & 449 & 173,535 & 99,348 & 389 & 409 & 165,568 & 91,314 \\
\hline & & $4: 08$ & $5: 04$ & & & & & & & & \\
\hline & & $5: 08$ & $5: 23$ & & & 151,463 & 144,192 & & & & \\
\hline & & $5: 51$ & $6: 16$ & & & & & & & & \\
\hline \multirow{5}{*}{26 April } & RF16 & $0: 40$ & 1:01 & 636 & 259 & & & & & 219,674 & 126,1002 \\
\hline & & $1: 05$ & $1: 30$ & 543 & 653 & 511 & 532 & & & & \\
\hline & & $1: 35$ & $2: 40$ & 534 & 617 & 396 & 436 & 462 & 761 & & \\
\hline & & $2: 48$ & $2: 52$ & & & & & & & & \\
\hline & & 4:09 & $4: 26$ & 500 & 531 & 369 & 207 & & & & \\
\hline \multirow[t]{4}{*}{27 April } & RF17 & $0: 47$ & $1: 35$ & 438 & 502 & 478 & 600 & & & 397 & 513 \\
\hline & & $1: 38$ & 2:09 & 465 & 440 & 369,1040 & 428,436 & 297,736 & 311,250 & $320,718,1381$ & $226,310,620$ \\
\hline & & $2: 11$ & $3: 11$ & 444 & 485 & 388 & 349 & 717 & 1280 & 348 & 280 \\
\hline & & $3: 33$ & $4: 20$ & 397 & 343 & 371,1083 & 462,393 & 65,161 & 75,58 & 371,904 & 295,667 \\
\hline \multirow[t]{4}{*}{28 April } & RF18 & $2: 18$ & $2: 31$ & 454,861 & 271 & 397 & 403 & & & 343,714 & 204,435 \\
\hline & & $2: 38$ & $3: 38$ & 464 & 383 & 450 & 265 & 282,536 & 154,246 & 397 & 417 \\
\hline & & $4: 17$ & $5: 28$ & 349 & 418 & & & & & & \\
\hline & & $5: 02$ & $5: 28$ & 349 & 418 & & & & & & \\
\hline
\end{tabular}

The mass flow rate $(\dot{m})$ can be calculated by multiplying the volumetric flow rate by the density:

$$
\dot{m}=0.58 k_{d} A \sqrt{(\gamma P \rho)} \text {. }
$$

After incorporation of the ideal gas law, the following relationships are obtained for the volumetric flow rate and the mass flow rate:

$$
Q=0.58 k_{d} A \sqrt{\left(\frac{\gamma R T}{M_{\text {air }}}\right)} \propto \sqrt{T}
$$

$$
\dot{m}=0.58 k_{d} A P \sqrt{\left(\frac{\gamma M_{a i r}}{R T}\right)} \propto \frac{P}{\sqrt{T}} .
$$

From the pressure-temperature flight data, it can be observed that for a $35 \%$ change in pressure, the absolute temperature in the AMS sampling line $(T)$ changes by $\sim 5 \%$. Therefore the largest effect of altitude change on the mass flow rate is a linear decrease due to decrease in pressure, while the volumetric flow rate stays nearly constant. 

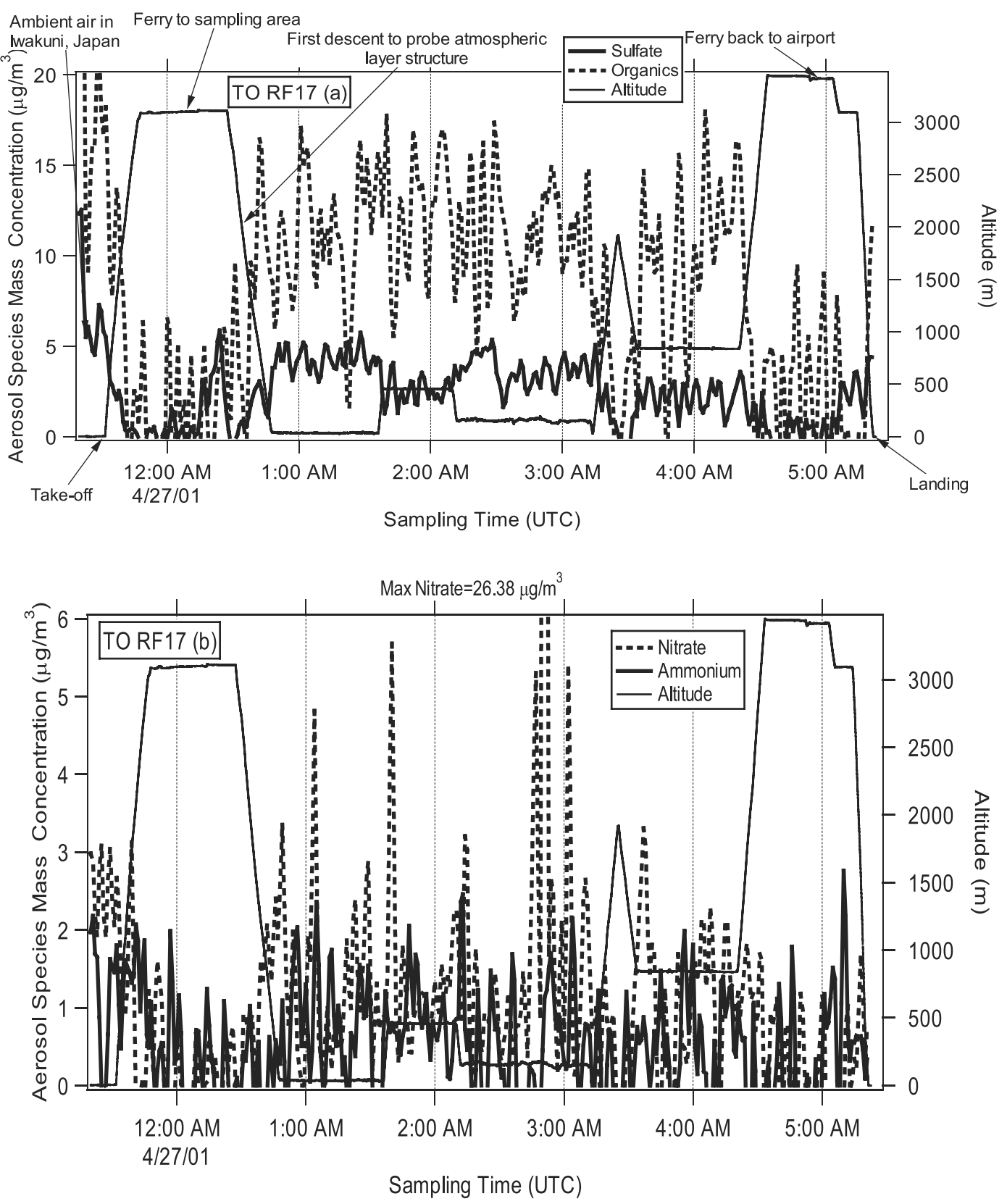

Figure 6. Concentration profiles of (a) sulfate and organics and (b) nitrate and ammonium for Twin Otter RF17.

[23] The volumetric flow rate into the AMS as configured in ACE-Asia is monitored by a laminar flowmeter, consisting of a differential pressure transducer that measures the pressure drop when the inlet flow-passes through a $1.3 \mathrm{~mm}$ ID and $9.5 \mathrm{~cm}$ long tube. The AMS computer software relates the voltage, $V$, that the differential pressure transducer produces in response to the pressure drop in the element to the volumetric flow rate through the laminar flowmeter, $Q$, using a linear calibration equation,

$$
Q=c+d V,
$$

where the offset, $c$, and slope, $d$, of equation (12) are determined by performing a linear regression between the measured voltage and the flow rate measured simultaneously with a highly precise automated bubble flowmeter (Gilibrator, Sensidyne, Clearwater, Florida).
[24] The pressure drop $(\Delta P)$ through the laminar flowmeter is related to the volumetric flow rate $(Q)$, dynamic viscosity $(\mu)$, radius $(R)$, and length $(l)$, of the laminar flowmeter as [Bird et al., 2002]

$$
\Delta P=\frac{8 Q \mu l}{\pi R^{4}} .
$$

Because the voltage read by the pressure transducer is proportional to the pressure drop across the laminar flowmeter, the following relation for parameter $d$ of equation (12) is obtained:

$$
d \propto \frac{\pi \mathrm{R}^{4}}{8 \mu \mathrm{l}} .
$$



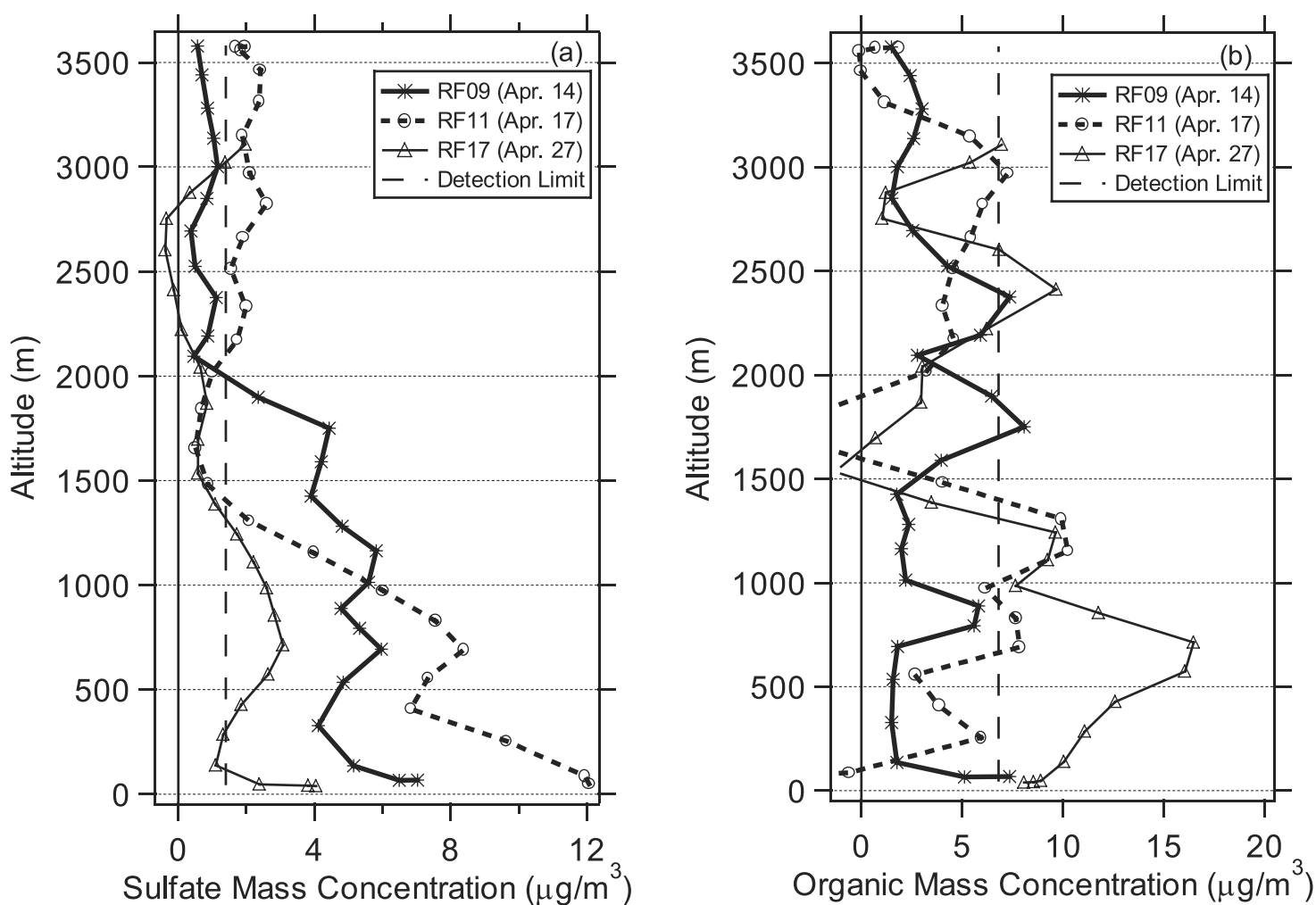

Figure 7. Concentration profiles of (a) sulfate and (b) organics for Twin Otter RF9 (during 3:18-3:43 UTC), RF11 (during 3:58-4:21 UTC), and RF17 (during 00:26-00:47 UTC). The magnitude of the apparent negative concentrations is indicative of the instrument detection limit for both species. This detection limit, as indicated on the plots, was significantly smaller for sulfate than for organics.

[25] Although the viscosity of air is independent of pressure, it does have a temperature dependence that can be expressed as [Hinds, 1999]

$$
\mu_{A l t}=\mu_{G r d}\left(\frac{T_{A l t}}{T_{G r d}}\right)^{0.74},
$$

where "Alt" and "Grd" refer to "at altitude" and "on the ground," respectively. Combining equations (12)-(15) results in the following equations that take into account the effect of temperature variations on the measured flow rate during flight

$$
\begin{gathered}
Q_{A l t}=c+\frac{d_{G r d} \mu_{G r d}}{\mu_{A l t}} V \\
Q_{A l t}=c+d_{G r d}\left(\frac{T_{G r d}}{T_{A l t}}\right)^{0.74} V .
\end{gathered}
$$

This temperature correction was $<4 \%$ for the observed temperature variations in the AMS sampling line during the Twin Otter flights in ACE-Asia.

\subsection{Variation of the AMS Internal Calibration Signal With Sampling Altitude (Pressure)}

[26] The sensitivity of the AMS to particle material can change with time due to various reasons, such as the normal decay in the gain of the electron multiplier with time and/or detuning of the ion optics. Decay of the electron multiplier can be monitored by pre and post flight calibrations and corrected for. Alternatively, in order to correct for both of these variations, the signal from a major air component $\left(\mathrm{N}_{2}\right.$ or $\mathrm{O}_{2}$ ) is used as an internal calibration standard of the AMS sensitivity [Allan et al., 2003b].

[27] In this study, the signal at $m / z 32\left(\mathrm{O}_{2}^{+}\right)$, referred to as the air beam $(\mathrm{AB})$, was used as the internal standard. However, with all else constant, the air beam signal intensity also varies as the pressure of the sampling air changes. This pressure-induced variation is large for aircraft AMS data, and needs to be removed first, in order to allow the use of the air beam signal as an internal standard for correction of AMS sensitivity fluctuations.

[28] Figure 5 shows the air beam signal recorded during a flight as a function of the pressure. Little variation in pre and post flight measurements of the air beam signal and the gain of the electron multiplier, as well as other internal diagnostics recorded during flight, indicated that the sensitivity fluctuations during this flight were negligible. The plot shows that the air beam changes approximately linearly with pressure. Thus, in order to remove pressure-induced variations from the air beam signal intensity, one can correct it as follows:

$$
\begin{gathered}
A B_{A l t}^{\text {Corr }}=A B_{A l t}+s\left(P_{\text {Grd }}-P_{A l t}\right) \\
\left(\frac{A B_{A l t}^{C o r r}}{A B_{\text {Grd }}}\right)=\left(\frac{A B_{A l t}^{t}}{A B_{\text {Grd }}}\right)+\left(\frac{s}{A B_{\text {Grd }}}\right)\left(P_{\text {Grd }}-P_{A l t}\right),
\end{gathered}
$$



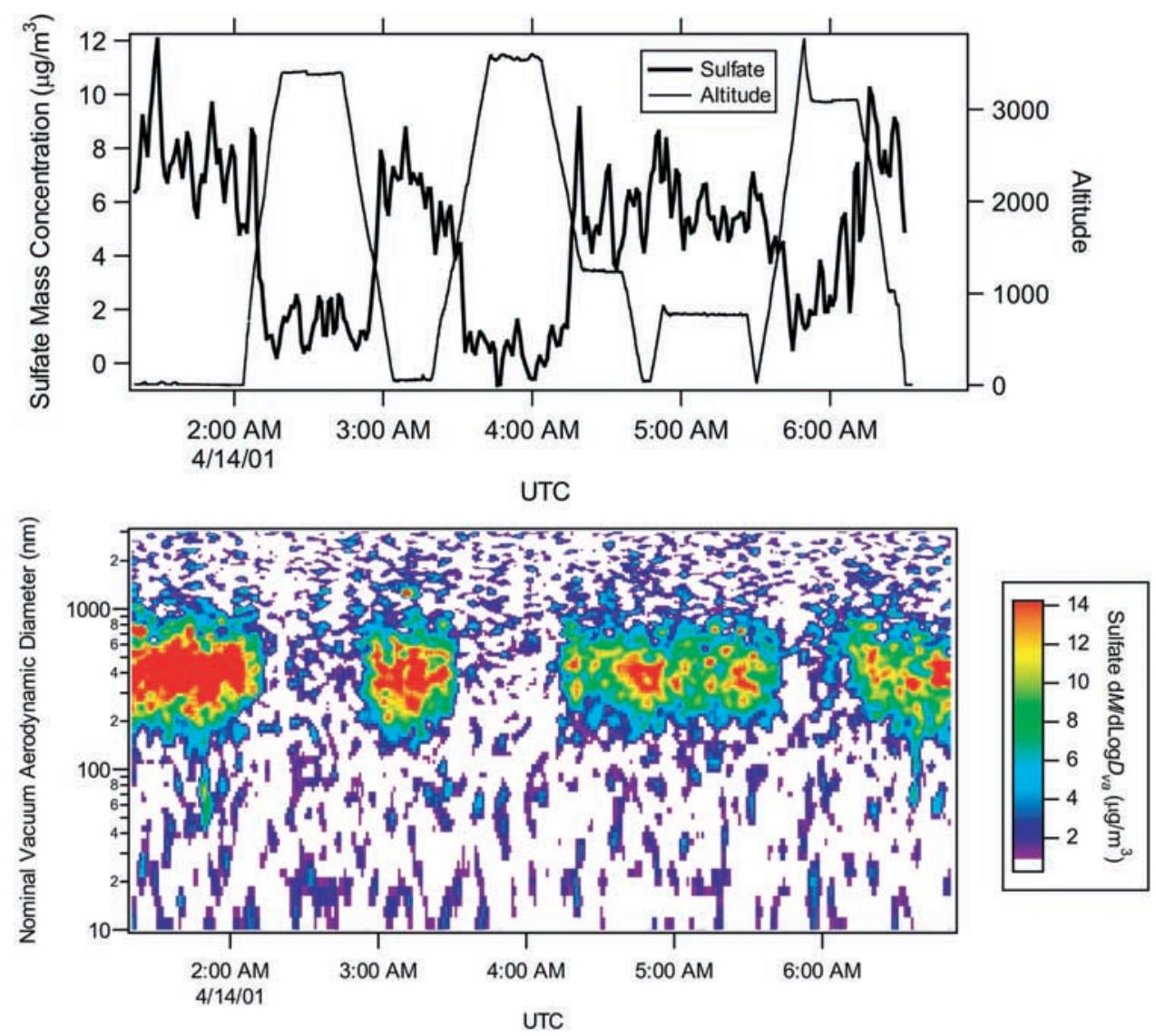

Figure 8. Time trend of total sulfate concentration and the size-resolved mass distribution of this species during Twin Otter RF9. Values below the detection limit in the image plot have been masked and marked by white areas. Owing to the integration over all sizes, the total sulfate concentration has better signal-to-noise than the size-resolved mass distribution. This is why the total concentration shows a clearly positive value for the cleaner layers that are below the detection limit on the size-resolved graph.

where $A B_{\text {Alt }}^{\text {Corr }}$ is the $\mathrm{AB}$ corrected for altitude (pressure) changes and $s$ is the slope of the linear fit as shown in Figure 5.

\section{Results of Airborne Aerosol Size and Composition Measurements}

[29] The main results of the AMS measurements for the Twin Otter (TO) flights during ACE-Asia are summarized in Tables 3, Tables 4, and 5.

\subsection{Aerosol Species Mass Concentrations}

[30] Continuous measurements of ammonium, sulfate, nitrate, and organics were made throughout each flight and recorded as 1-min averages (see section 2.3). As an example, Figure 6 shows how the Twin Otter altitude and aerosol concentration profiles of these species evolved during Twin Otter research flight 17 (27 April 2001).

[31] All flights started with a climb immediately after take off to an altitude of $\sim 3.7 \mathrm{~km}$, followed by a "transit" or "ferry" leg to an offshore location of interest, as shown in Figures 1 and 6. Upon arrival to the working area, the Twin Otter performed a descent leg to the minimum altitude possible $(\sim 25 \mathrm{~m})$ in order to obtain a profile of the thermodynamic and aerosol structure of the atmosphere. The Twin Otter flight scientist then chose some layers for extended characterization of the aerosol properties and horizontal structure. Additional ascents and descents were also performed in order to acquire vertical profiles of radiative properties with the onboard Sun photometer and radiometers [Schmid et al., 2003; Wang et al., 2002]. The flight ended with a climb to the maximum Twin Otter altitude of $\sim 3700 \mathrm{~m}$, a ferry leg back to Iwakuni, and a rapid descent profile over Iwakuni.

[32] Generally, higher concentrations of submicron aerosol sulfate, organics, and nitrate were measured on the ground before takeoff as compared with those during transit $(\sim 3500 \mathrm{~m}-3700 \mathrm{~m})$. Concentration profiles of sulfate and organics during one of the vertical profiles at an offshore location in research flights 9,11 , and 17 are shown in Figure 7. The concentration of sulfate and organics increased sharply as the aircraft ascended or descended through pollution layers. Figure 8 shows the time trend of total sulfate concentration as well as the size-resolved mass distribution for this species for research flight 9. This figure illustrates the typical results for sulfate in the majority of the Twin Otter flights: the total concentration of sulfate (as well as the size-resolved mass distribution signal) increases 


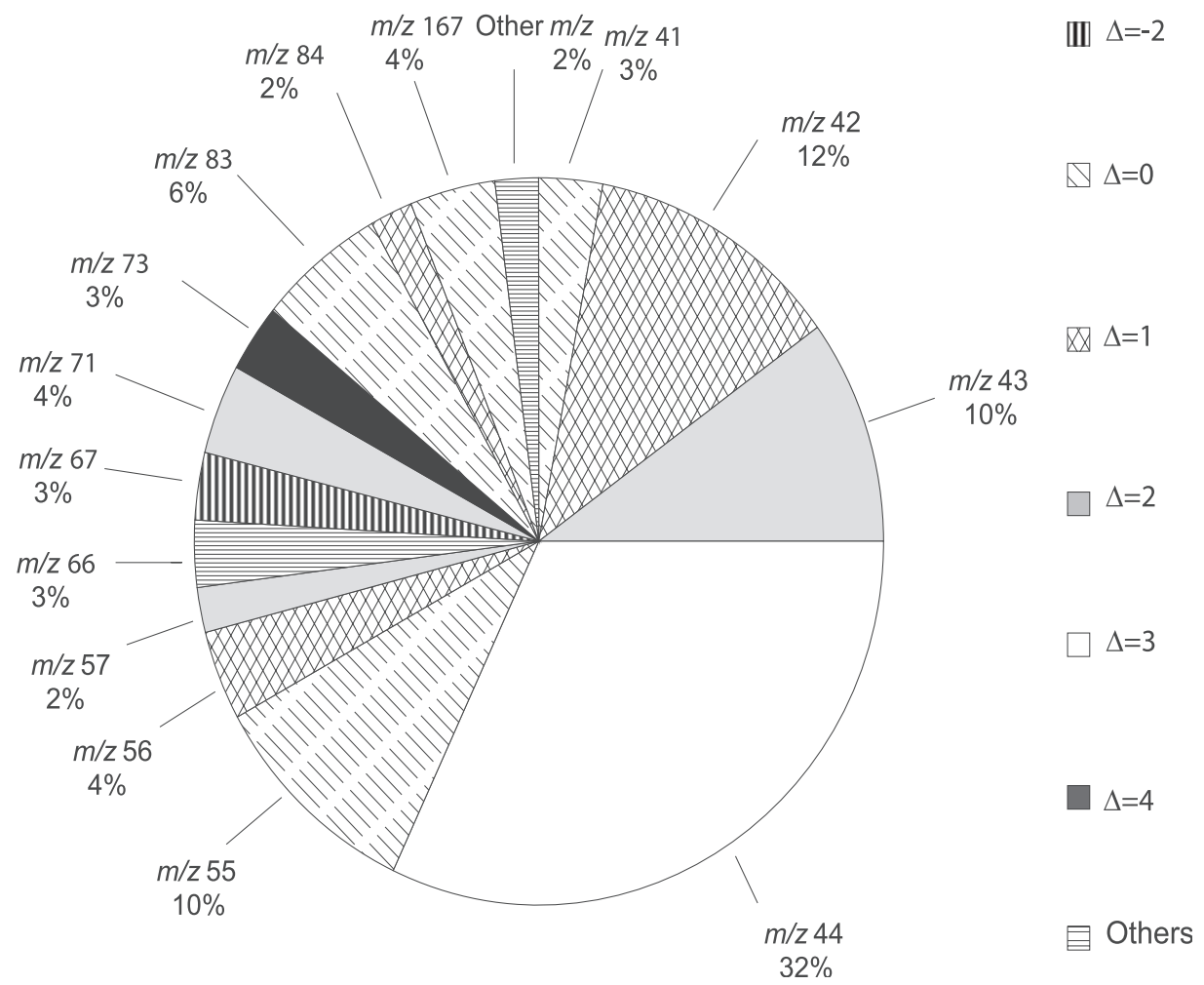

Figure 9. Pie chart representation of major organic fragments and their contribution (as a percentage) to the total estimated organics mass concentration. Ion series analysis indicates $\sim 57 \%$ of organics mass is due to aliphatic organics with $\Delta=0-2(\mathrm{~m} / \mathrm{z} 41-43,55-57,71,83-84$, and 167$)$ and $35 \%$ is due to oxygenated organics with $\Delta>2(\mathrm{~m} / \mathrm{z} 44$ and 73$)$.

(decreases) sharply as the plane enters (leaves) pollution layers. Although in most cases pollution layers exhibited elevated concentrations of both organics and sulfate, Figure 7 contains an example of an organic pollution layer at $\sim 1200 \mathrm{~m}$ during RF 17 when sulfate loading is low. Figure 9 is a representation of major organic fragments considered in the analysis along with their average contribution to the total organic mass, expressed as a percentage. Almost $90 \%$ of the total organic mass signal during the ACE-Asia flight layers where organics were detected is observed at $\mathrm{m} / \mathrm{z}$ corresponding to $\Delta=0-3$ (mainly $\mathrm{m} / \mathrm{z}=$ $41-44,55-57,71,83-84$, and 167). This would be consistent with an organic aerosol component containing some oxygenated species and some saturated hydrocarbons, as would be expected for secondary organic aerosols and primary combustion emissions, respectively. Since only 3\% of the total organic mass signal during the ACE-Asia flight layers where organics were detected is observed at $\mathrm{m} / \mathrm{z}$ corresponding to $\Delta<0$, unsaturated organics were not present in significant mass concentrations. This observation can tentatively be explained by the long transport time between emissions and detection, during which unsaturated aerosol species may have been oxidized by atmospheric $\mathrm{O}_{3}$.

[33] During most of the flights, $2-5$ pollution layers were observed from surface up to an altitude of $\sim 3700 \mathrm{~m}$. Back-trajectory analysis indicated that air masses sampled on the constant altitude legs of Twin Otter flights during 8 28 April had originated $\sim 60 \%$ of the times from $\mathrm{E} / \mathrm{NE}$ China and $\sim 30 \%$ of the times from Korea (G.R. Carmi- chael, University of Iowa, personal communication, 2002). Pollution layers with influence of emissions from China were found up to $\sim 3700 \mathrm{~m}$ while pollution layers with influence from Korea were generally found at altitudes $<2000 \mathrm{~m}$. The AMS measurements during ACE-Asia indicated that the average concentrations of species in pollution layers below $1000 \mathrm{~m}\left(2.75 \mu \mathrm{g} \mathrm{m}^{-3}\right.$ for sulfate, $1.05 \mu \mathrm{g} \mathrm{m}^{-3}$ for nitrate, and $5.26 \mathrm{\mu g} \mathrm{m}^{-3}$ for organics) were higher than average concentrations in higher altitude pollution layers although occasionally high concentrations of sulfate or organics were observed at $1000-3000 \mathrm{~m}$. On the other hand, ammonium average concentrations on constant altitude pollution legs were lower at altitudes less than $1000 \mathrm{~m}$.

\subsection{Size-Resolved Aerosol Species Mass Distributions}

[34] The mass distributions for nonrefractory species for particles in the range of $40 \mathrm{~nm}$ to $\sim 1 \mu \mathrm{m}$ vacuum aerodynamic diameter were recorded by the AMS in TOF mode every minute. The ammonium mass distribution, however, is valid only from about $100 \mathrm{~nm}$ to $1 \mu \mathrm{m}$ since the signal from this species at smaller apparent particle sizes at $\mathrm{m} / \mathrm{z}$ $16 \mathrm{amu}$ is masked by the tail of the signal from $\mathrm{O}^{+}$ions from the air beam.

[35] The size resolution of the AMS is defined as the ratio of the vacuum aerodynamic diameter to the observed full width half maximum (FWHM) that would be obtained when sampling monodisperse particles. This quantity is size-dependent. With the configuration of the AMS during ACE-Asia, the size resolutions at $100 \mathrm{~nm}, 300 \mathrm{~nm}$, and 

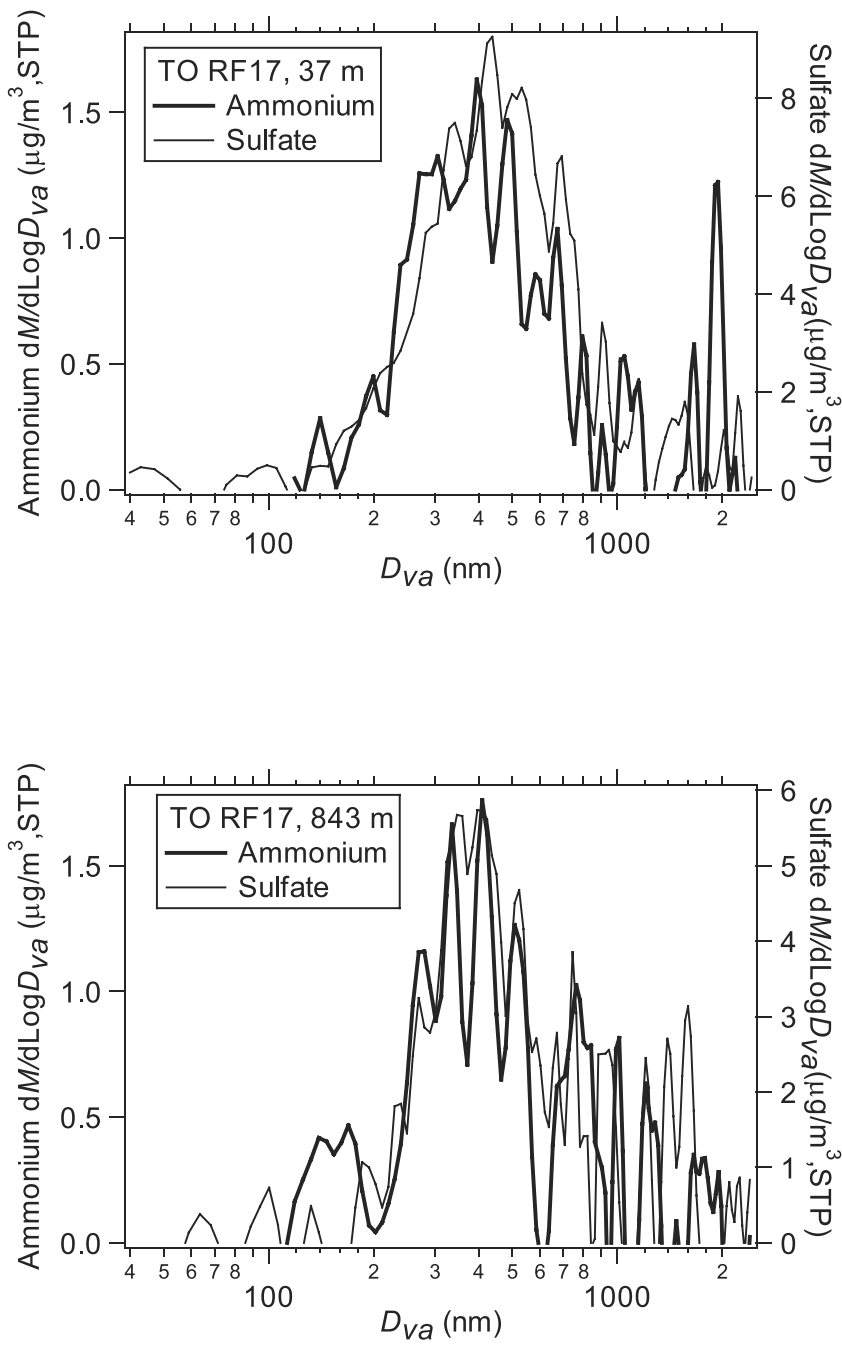

Figure 10. Average ammonium and sulfate mass distributions during Twin Otter RF17 (37 m (00:47-1:35 UTC) and $843 \mathrm{~m}(3: 33-4: 20 \mathrm{UTC}))$.

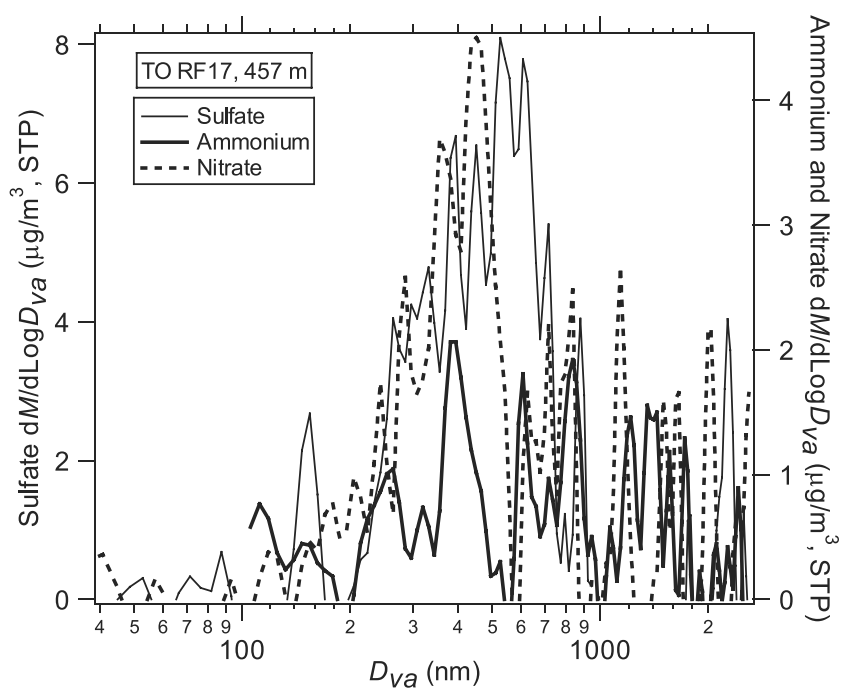

Figure 11. Average mass distributions of ammonium, sulfate, and nitrate during Twin Otter RF17 (457 m (1:382:09 UTC)).

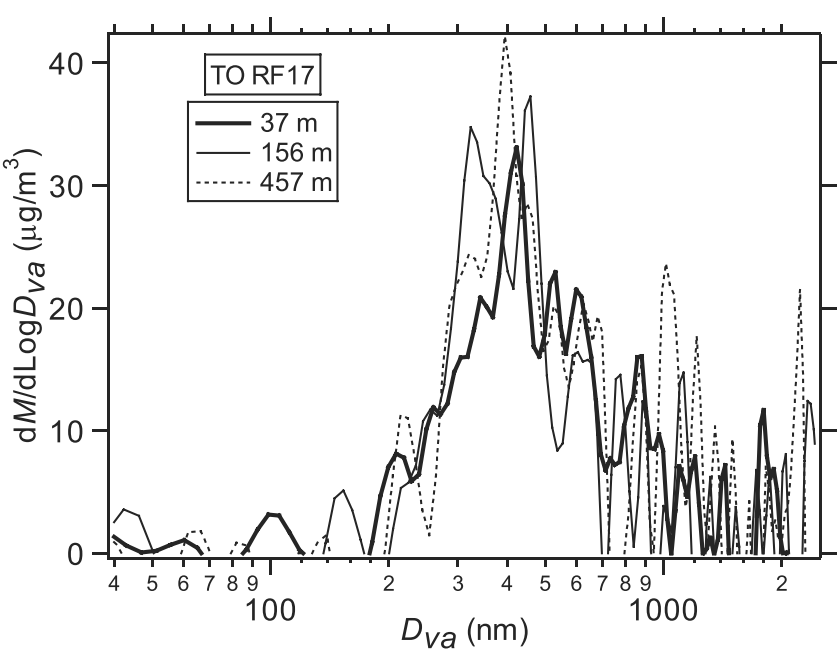

Figure 12. Average mass distribution for species with fragments at $m / z=44$ amu during Twin Otter RF17 (37 m (00:47-1:35 UTC), $156 \mathrm{~m}(2: 11-3: 11 \mathrm{UTC})$, and $843 \mathrm{~m}$ (3:33-4:20 UTC)).

$1000 \mathrm{~nm}$ are estimated to be $2,2.9$, and 6.5 , respectively. These values of the AMS size resolution are equivalent to FWHM values of about $50 \mathrm{~nm}, 105 \mathrm{~nm}$, and $155 \mathrm{~nm}$ when monodisperse distributions of $100 \mathrm{~nm}, 300 \mathrm{~nm}$, and $1000 \mathrm{~nm}$ vacuum aerodynamic diameter are sampled. The higher chopper duty cycle of the AMS during ACE-Asia ( $4 \%$ versus $2 \%$ typically used in ground-based field studies) reduced the resolution compared to that in other studies. There is always a tradeoff between size resolution and signal-to-noise ratio (SNR) in the TOF mode, and in this study, a lower resolution was tolerated in order to increase SNR and time resolution.

[36] The horizontal variability within each layer was found to be small ( $\sim 45 \%$ relative standard deviation), compared to the differences between layers (factor of 2-15). Since the horizontal variability in each layer was relatively small, the mass distributions presented here have been averaged during constant altitude legs in order to maximize their signal-to-noise ratios.

[37] Figure 10 shows the mass distribution of ammonium and sulfate obtained during Twin Otter RF17 for two legs at altitudes of 37 and $843 \mathrm{~m}$. The fact that both species are correlated in time and size suggests that they were both present on the same particles (i.e, these species are likely internally mixed in the aerosols), and that the sulfate aerosols were at least partially neutralized. However, the aerosols may not be completely neutralized on these two layers because the average molar ratio of positive to negative ion charges of the nonrefractory ions of ammonium, sulfate, and nitrate, i.e, $\mathrm{NH}_{4}^{+} /\left(2 \mathrm{SO}_{4}^{2-}+\mathrm{NO}_{3}^{-}\right)$, is 0.34 and 0.49 , at $37 \mathrm{~m}$ and $843 \mathrm{~m}$, respectively. The average molar ratio of positive to negative ion charges of nonrefractory ions over 20 constant altitude legs of the Twin Otter flights at altitudes less than $1000 \mathrm{~m}$ was calculated to be $\sim 0.9$, indicating that the aerosols sampled on most of these layers were most likely not completely neutralized. One should keep in mind, however, that this estimate of acidity of aerosols is based only on the AMS measurements of nonrefractory ions. The current detection technique of the 

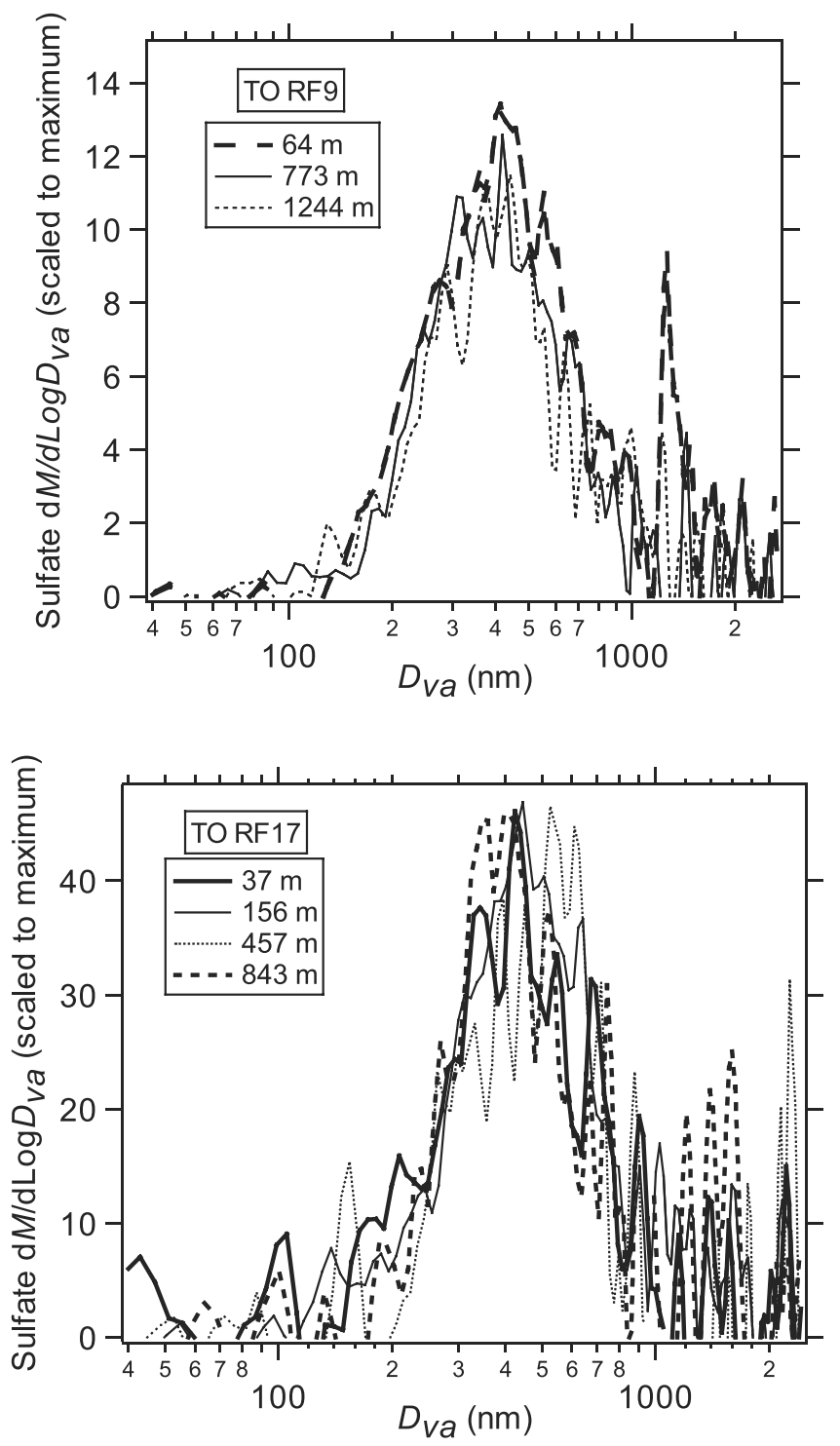

Figure 13. Average sulfate mass distributions scaled to maximum for Twin Otter RF9 (64 m (3:04-3:19 UTC), 773 $\mathrm{m}$ (4:54-5:26 UTC), and $1244 \mathrm{~m}(4: 20-4: 35 \mathrm{UTC}))$ and Twin Otter RF17 (37 m (00:47-1:35 UTC), 156 m (2:11$3: 11$ UTC), $457 \mathrm{~m}$ (1:38-2:09 UTC), and $843 \mathrm{~m}(3: 33-$ 4:20 UTC)).

AMS does not allow the detection of refractory components of the aerosols. In addition, organic acids that may be present on the aerosols will be detected but cannot be unequivocally identified as acids. Thus possible presence of refractory ions, such as sodium, calcium, and carbonate, or organic acids on submicron aerosols will contribute an uncertainty to the estimate of the acidity of aerosols.

[38] Figure 11 shows a comparison of the mass distributions of ammonium, sulfate, and nitrate during a $31 \mathrm{~min}$ leg on RF17 at $457 \mathrm{~m}$ : on this leg, ammonium and nitrate show a bimodal distribution (modes at $\sim 310 \mathrm{~nm}$ and $720 \mathrm{~nm}$ ) while sulfate does not. These data indicate that on this leg ammonium was probably associated with both nitrate and sulfate, i.e, two externally mixed aerosol populations. The average molar ratio of positive to negative charges of the nonrefractory ions on this leg was calculated to be 0.6 .

[39] Figure 12 shows the mass distribution obtained from the TOF signal at $\mathrm{m} / \mathrm{z} 44$ for three of the constant altitude legs of RF17. This signal has been scaled to the total organic concentration such that the area under the curve of $\mathrm{d} M / \mathrm{d} \log D_{v a}$ versus $\log D_{v a}$ for a constant altitude leg is the same as the average organic mass concentration estimated from MS data (including all organic peaks, not just $m / z 44$ ) for that leg since mass distribution measurements of other organic fragments did not have enough signal-to-noise ratio in this case. Organic acids and other oxygenated organics, the fragments of which have been detected in aerosols [Seinfeld and Pandis, 1998], and other compounds such as amides would give fragments at $m / z 44$ amu upon electron impact ionization (R. Alfarra et al., manuscript in preparation, 2002). The fact that this mass distribution shows a single mode at $\sim 400 \mathrm{~nm}$, similar to sulfate in this same layer and with a similar width, is consistent with internally mixing of sulfate and organics in aerosols that have aged during transport.

[40] The measured mass distribution of $\mathrm{m} / \mathrm{z} 44$ does not show much variability in its mode diameter with altitude or on different days. Similar behavior is observed for the sulfate mass distribution at different altitudes, which is shown in Figure 13 for RF9 and RF17. During RF9, the mode of the three size distributions is $\sim 400 \mathrm{~nm}$ diameter, while during RF17 the mode is $\sim 400-465 \mathrm{~nm}$ for different altitudes. However, these variations are within the resolution of the AMS size measurement as described earlier. As reported in Table 5, the sulfate mass distribution on different legs was relatively uniform from day to day with a mode in a range of 400-500 nm vacuum aerodynamic diameter.

[41] Sulfate and ammonium mass distributions measured at altitudes typical of marine boundary layers (i.e, $<100 \mathrm{~m}$ ) and pollution layers are compared in Figure 14 (scaled to the maximum). As shown in Figures $14 a-14 b$, sulfate mass distributions show a mode at $\sim 400 \mathrm{~nm}$ for both marine boundary layers and pollution layers. Similar mass distributions are observed for ammonium in the marine boundary layers and pollution layers although the distributions are noisier (Figures 14c-14d).

\section{Comparison of Twin Otter AMS and DMA Data}

[42] The aerosol size distribution in the range of $15 \mathrm{~nm}-$ $1 \mu \mathrm{m}$ was measured by two differential mobility analyzers (DMAs) aboard the Twin Otter. Operation of the DMAs during ACE-Asia has been described by Wang et al. [2002]. The DMAs were mounted in the main cabin of the Twin Otter next to the AMS. One of the DMAs measured the aerosol size distribution at ambient relative humidity, while the other measured the "dry" size distribution after passing the aerosol stream through a Nafion drier prior to measurement. Since no attempt has been made to derive the aerosol water concentration from the AMS data, the dry aerosol size distributions and volume concentrations from the DMA are compared with the size distributions and total mass concentrations of the AMS. Figure 15a shows the time trend in the AMS total mass concentration (i.e, sum of sulfate, nitrate, ammonium, and organics mass concentration 

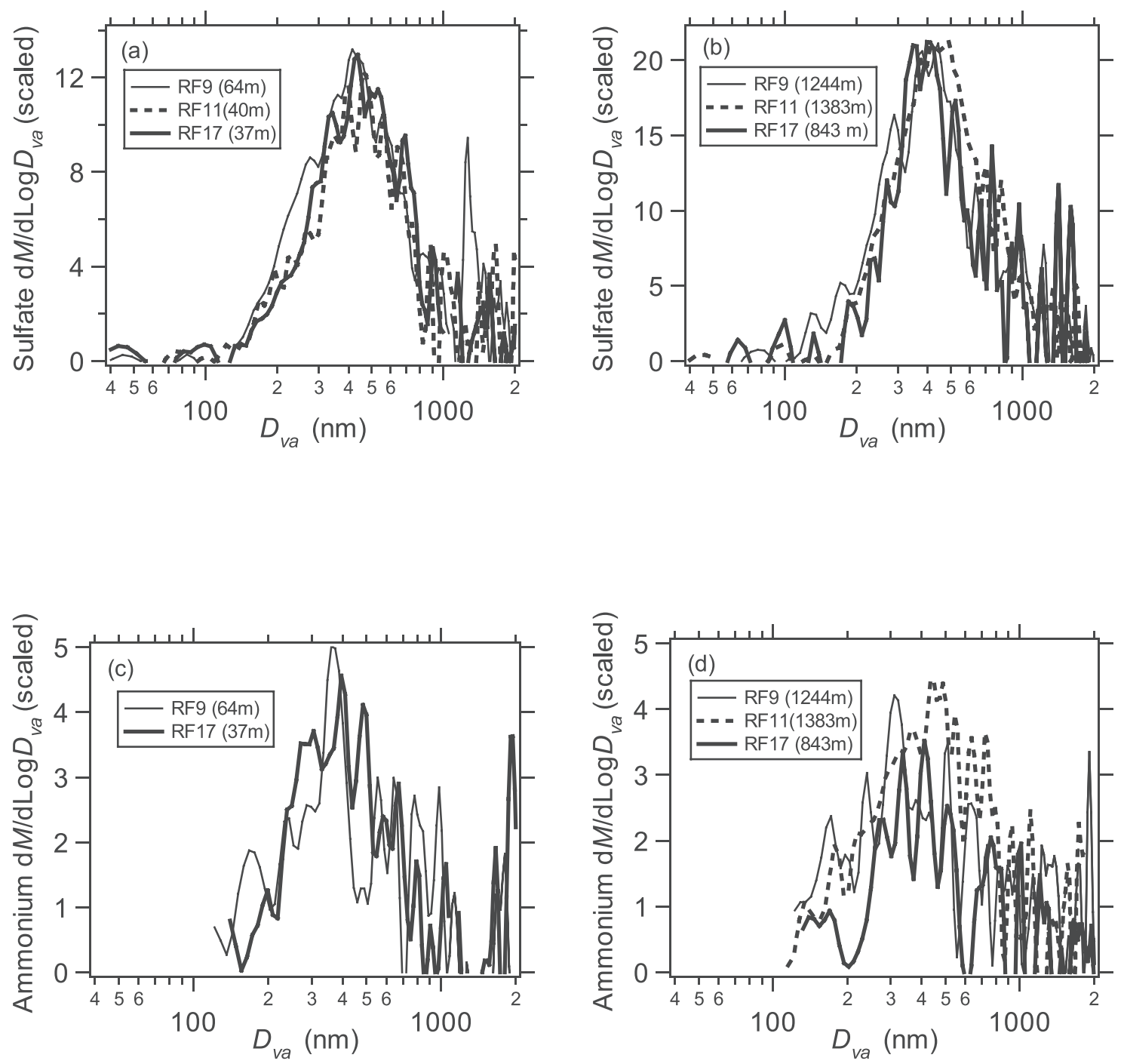

Figure 14. Average sulfate and ammonium mass distributions for (a and c) marine boundary layer and (b and d) pollution layers on Twin Otter RF9, RF11, and RF17 (scaled to the maximum, i.e, scaled to RF9 distribution for marine layer sulfate and ammonium, RF11 distribution for pollution layer sulfate, and RF9 distribution for pollution layer ammonium).

(in $\mu \mathrm{g} \mathrm{m}^{-3}$ ) and the DMA dry volume concentration (in $\mu \mathrm{m}^{3} \mathrm{~cm}^{-3}$ ). These two quantities are numerically identical for an aerosol composed of nonporous spherical particles of unit specific density (i.e, with a density of $1 \mathrm{~g} \mathrm{~cm}^{-3}$ ). For spherical particles with a density different from unity, the ratio of the AMS mass to the DMA volume is the material density of the aerosol, while nonspherical particles result in lower apparent density [Jimenez et al., 2003a]. The two measurements follow each other closely in time. Figure 15b shows the linear fit of the AMS mass concentration with respect to the DMA volume concentration, with the slope indicating the apparent aerosol density, averaged throughout the flight, assuming that all the aerosol mass has been accounted for by the AMS. An independent estimate of aerosol density can be derived from the AMS measurements, assuming average densities for each of the chemical species. Table 6 tabulates ratios of the AMS mass to DMA volume concentration for a few flights at different altitudes and air masses, and the expected aerosol density based on sulfate, ammonium, and organics mass concentrations measured by the AMS, with the assumption that the mixture volume is the sum of the volumes of the individual components. However, since the AMS as operated in this study was unable to detect refractory aerosol components, it is more appropriate to compare values of this ratio to the estimated density on the days when there was little influence of dust or sea-salt in the sampled air mass. Aerosol extinction coefficients as well as $\mathrm{Si}, \mathrm{Ca}, \mathrm{Mg}, \mathrm{Al}$, and $\mathrm{Cl}$ concentrations measured by a total filter aboard the Twin Otter indicate contributions from larger size aerosols of dust and/or sea salt during RF9 and RF11 [Wang et al., 2002] (S. Gao and D. Hegg, University of Washington, personal communication, 2002). During RF14 and RF17, when a significant influence of dust or sea-salt was not detected, the apparent density obtained from the ratio of the AMS mass to DMA volume matches with the estimated aerosol density based on the AMS mass concentrations of sulfate, ammonium, and organics to within $15-23 \%$. This discrepancy may be due to 

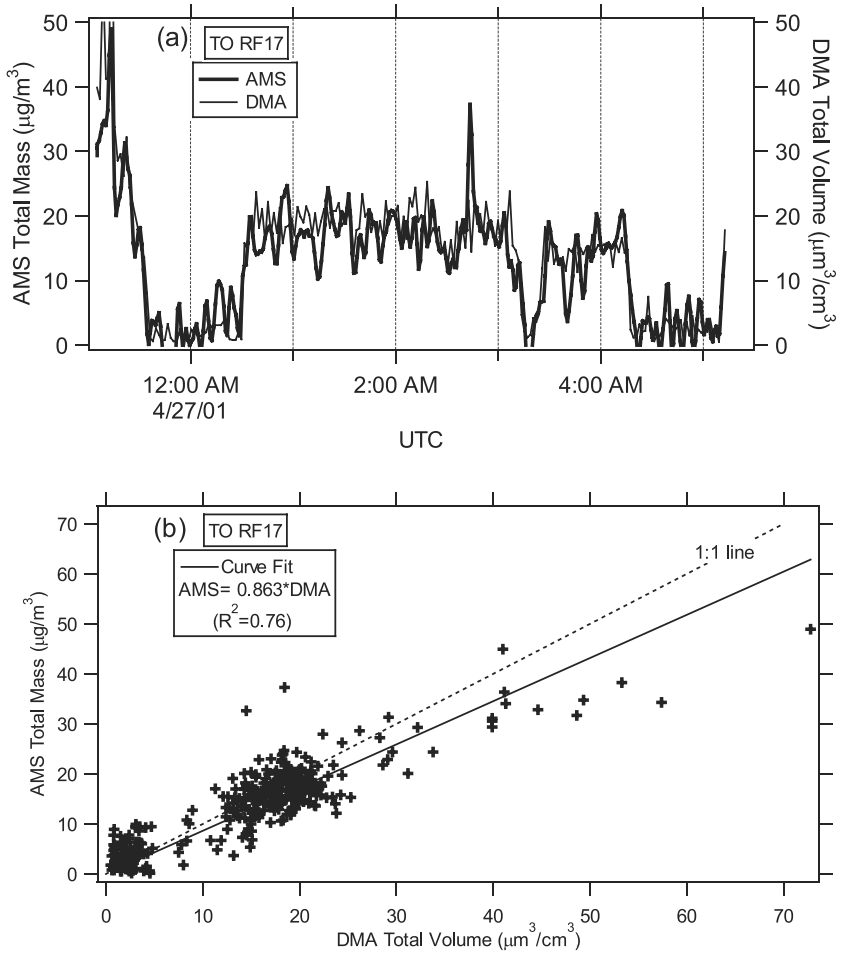

Figure 15. Time trend of the AMS total mass concentration and DMA total dry aerosol volume concentration on (a) Twin Otter RF17 and (b) the linear fit to the data.

reduced particle transmission in the lens system of the AMS for larger size or irregularly shaped particles. Presence of irregularly shaped particles affects the size (volume) information obtained from the DMA as well since the DMA sizes particles based on their mobility diameter. The mobility diameter is different from physical diameter if the particles are nonspherical because the drag force on nonspherical particles is different than on spherical ones. Figure 16 compares the summed mass distributions of the sulfate and organics measured by the AMS with the total dry volume distribution measured by the DMA versus estimated physical diameter, at two different altitudes during Twin Otter RF17. Vacuum aerodynamic diameter of the AMS mass distributions has been converted to physical diameter using the calculated density based on sulfate, ammonium, and organics mass concentration in the AMS mass spectral data, assuming additive volumes, and a dynamic shape factor of 1.0 (i.e, assuming spherical particles). At both altitudes, the AMS mass distributions show modes at $340-390 \mathrm{~nm}$ while the DMA volume distributions modes appear at $280 \mathrm{~nm}$. This discrepancy may be due to an incorrect assumption for the density of the organic species $\left(0.9 \mathrm{~g} \mathrm{~cm}^{-3}\right)$ in converting AMS vacuum aerodynamic diameter to physical diameter or to the presence of some water in the particles analyzed by the AMS. The effective densities needed to match the AMS and DMA distributions recorded at $156 \mathrm{~m}$ and $843 \mathrm{~m}$ are $1.6 \mathrm{~g} \mathrm{~cm}^{-3}$ and $1.3 \mathrm{~g} \mathrm{~cm}^{-3}$, respectively, rather than $1.14 \mathrm{~g} \mathrm{~cm}^{-3}$ and $1.09 \mathrm{~g} \mathrm{~cm}^{-3}$ that have been used in the analysis. In addition, presence of water on the particles affects the vacuum aerodynamic diameter observed by the AMS while it does not affect the dry diameter measured by the DMA.

\section{Comparison With Previous Measurements in the Region}

[43] Levels and relative amounts of aerosol sulfate, nitrate, ammonium, and organics reflect atmospheric processing and aging that take place as Asian emissions of aerosols and aerosol precursor gases are advected away from continental sources. Since both observations and atmospheric chemical transport modeling studies of aerosol concentrations and compositions in this region have been reported before, it is possible to place the current ACE-Asia measurements within the context of past studies. Measurements at Cheju Island, Korea [Carmichael et al., 1997; Chen et al., 1997], Nara, Japan [Matsumoto and Okita, 1998], and Sapporo, Japan [Kaneyasu et al., 1995] exemplify results of observational studies in the region.

Table 6. Ratio of the AMS Total Mass Concentration to DMA Volume Concentration, Estimated Density Based on Individual Species Mass Concentration Measurements of the AMS, as Well as Estimated Density by Comparing AMS $D_{v a}$ with DMA $D_{p}$ on Several Constant-Altitude Legs for Twin Otter Research Flights During ACE-Asia

\begin{tabular}{|c|c|c|c|c|c|c|}
\hline $\begin{array}{l}\text { Date of the } \\
\text { Twin Otter Flight }\end{array}$ & $\begin{array}{l}\text { Time, } \\
\text { UTC }\end{array}$ & $\begin{array}{c}\text { Altitude, } \\
\mathrm{m}\end{array}$ & $\begin{array}{c}\text { Estimated Density } \\
\text { From Ratio of } \\
\text { AMS Mass to DMA Volume }\end{array}$ & $\begin{array}{l}\text { Estimated Density From } \\
\text { AMS Speciation, } \\
\mathrm{g} \mathrm{cm}^{-3}\end{array}$ & $\begin{array}{l}\text { Estimated Density } \\
\text { by Comparing AMS } D_{v a} \\
\text { and DMA } D_{p}, \mathrm{~g} \mathrm{~cm}^{-3}\end{array}$ & Air Mass \\
\hline \multirow[t]{4}{*}{14 April 2001 (RF 09) } & $3: 04-3: 19$ & 64 & 0.58 & 1.54 & 1.48 & NE China \\
\hline & $4: 20-4: 35$ & 1244 & 0.95 & 1.45 & 1.44 & NE China \\
\hline & $4: 54-5: 26$ & 773 & 0.65 & 1.59 & 1.46 & NE China \\
\hline & $5: 53-6: 10$ & 3093 & 0.44 & 1.39 & & \\
\hline \multirow[t]{3}{*}{17 April 2001 (RF 11) } & $4: 33-4: 47$ & 2805 & 0.65 & 1.77 & & SE China \\
\hline & $4: 56-5: 29$ & 1383 & 1.16 & 1.59 & 1.33 & E China \\
\hline & $5: 38-5: 52$ & 40 & 0.86 & 1.60 & 1.04 & E China \\
\hline \multirow[t]{4}{*}{23 April 2001 (RF 14) } & $1: 21-1: 32$ & 26.5 & 1 & 1.30 & & \\
\hline & $1: 35-2: 54$ & 607 & 1.03 & 1.27 & 1.62 & NE China/N Korea \\
\hline & $2: 58-3: 16$ & 30.5 & 1.14 & 1.29 & 1.55 & \\
\hline & $4: 03-4: 24$ & 604 & 1.36 & 1.22 & 1.62 & NE China/N Korea \\
\hline \multirow[t]{4}{*}{27 April 2001 (RF 17) } & $00: 47-1: 35$ & 37 & 0.90 & 1.17 & 1.56 & \\
\hline & 1:38-2:09 & 457 & 0.91 & 1.08 & 1.55 & S Korea \\
\hline & $2: 11-3: 11$ & 156 & 0.97 & 1.14 & 1.59 & S Korea/N China \\
\hline & $3: 33-4: 20$ & 843 & 0.97 & 1.09 & 1.32 & S Korea/N China \\
\hline
\end{tabular}



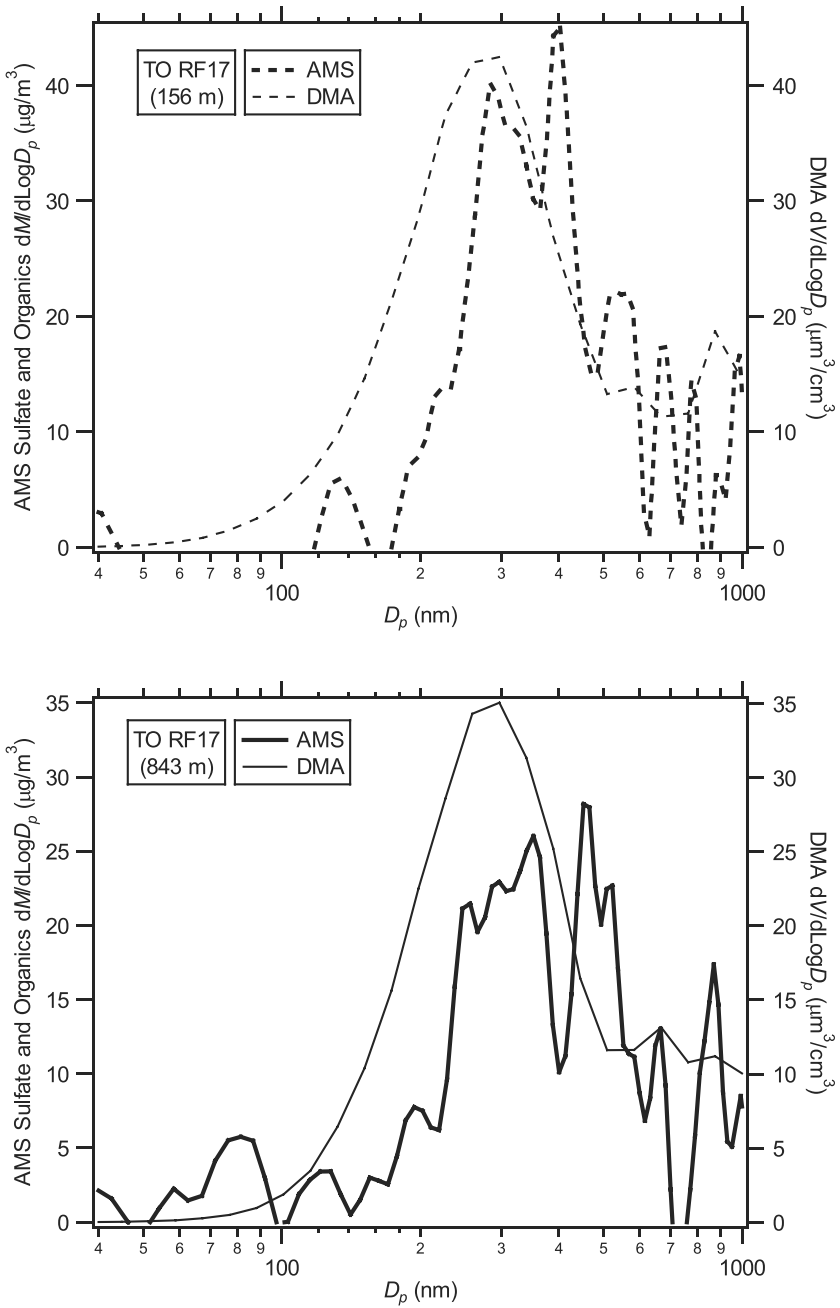

Figure 16. Comparison of AMS average mass distribution of sulfate and organics and DMA average total dry aerosol volume distribution on RF17 (156 m (2:11-3:11 UTC) and $843 \mathrm{~m}(3: 33-4: 20$ UTC)).

[44] The measurements at Cheju are more representative of air masses from Korea and China. Cheju Island, Korea, is located at $33^{\circ} \mathrm{N}-126^{\circ} \mathrm{E}$ in the East China Sea, $\sim 100 \mathrm{~km}$ south of mainland Korea, $\sim 500 \mathrm{~km}$ east-northeast of Shanghai, China, $\sim 250 \mathrm{~km}$ west of Kyushu, Japan, and $\sim 1000 \mathrm{~km}$ north-northeast of Taichung, Taiwan. During winter, airflow to Cheju is generally from north-northwest; thus sampled air is influenced by northern China as well as
Korea. During springtime, air masses at Cheju originate predominantly from northern and eastern China. Carmichael et al. [1997] and Chen et al. [1997] presented aerosol composition data obtained from tape filters at Cheju during March 1992-February 1995. These measurements show that maximum aerosol concentrations are observed in spring during dust storm events and continental outflows associated with high-pressure cold fronts. Among various aerosol species, calcium, nitrate, and potassium are maximum in spring. Although non-sea-salt (NSS) sulfate and ammonium show less seasonal variability than the previous species, their concentrations are higher in winter and spring and lower in summer. In general, observations at Cheju indicate that if the air masses originate from north-central China traveling behind high-pressure cold fronts, high concentrations of $\mathrm{SO}_{4}^{2-}, \mathrm{NO}_{3}^{-}$, and $\mathrm{Ca}^{2+}$ occur. Air masses from the industrial regions of eastern China are characterized by high $\mathrm{SO}_{4}^{2-}$ and $\mathrm{NO}_{3}^{-}$concentrations and low $\mathrm{Ca}^{2+}$. However, air masses from southern Japan and Korea are associated with high $\mathrm{SO}_{4}^{2-}$ but low $\mathrm{NO}_{3}^{-}$and $\mathrm{Ca}^{2+}$.

[45] Other studies have characterized the ground-level aerosol species concentrations in Japan, which should reflect Japanese emissions and probably also advection from the Asian mainland. For example, Matsumoto and Okita [1998] presented results of Annular Denuder System (ADS) sampling in Nara, Japan during June 1994-May 1995. Nara is located at $34^{\circ} \mathrm{N}-135^{\circ} \mathrm{E}, \sim 50 \mathrm{~km}$ east of Osaka. Among the gaseous species, sulfur dioxide and nitrous acid concentrations were higher in winter while nitric acid concentration was higher in summer. Although the observed particulate nitrate concentration was higher in winter and spring, particulate sulfate and total nitrate (nitric acid + particulate nitrate) were higher in the summer, the reason being the summertime airflow from Osaka toward Nara which transports the pollutants to Nara city.

[46] Kaneyasu et al. [1995] reported results of filter pack measurements at two sites in the city of Sapporo, Japan during June 1987-December 1988. Sapporo is located on the west coast of Hokkaido, the northernmost of the four main Japanese islands, bordered by the Japan Sea on the north and mountains on the west and south. Measurements were collected at two stations: Higashi-Tsukisamu, at the northern end of Sapporo, and Shinoro, at the southern end of Sapporo. The wind direction in Sapporo is southeasterly in summer and northwesterly in winter; thus Shinoro is downwind of the urban area in summer, and HigashiTsukisamu is downwind from the city in winter. Measurements at Sapporo indicate that the $\mathrm{PM}_{10}$ mass concentration at both locations was higher during winter and spring and

Table 7. Average Aerosol Concentrations Previously Measured in the Region

\begin{tabular}{|c|c|c|c|c|c|c|c|c|c|c|c|c|}
\hline Location & $\mathrm{SO}_{4}^{2-}$ & $\mathrm{NO}_{3}^{-}$ & $\mathrm{NH}_{4}^{+}$ & $\mathrm{Na}^{+}$ & $\mathrm{K}^{+}$ & $\mathrm{Ca}^{2+}$ & $\mathrm{Mg}^{2+}$ & $\mathrm{Cl}^{-}$ & $\mathrm{TC}$ & $\mathrm{EC}$ & $\begin{array}{c}\mathrm{NH}_{4}^{+} /\left(2 \mathrm{SO}_{4}^{2-}+\mathrm{NO}_{3}^{-}\right) \\
\text {Molar Ratio } \\
\end{array}$ & $\begin{array}{l}\mathrm{NO}_{3}^{-} / \mathrm{SO}_{4}^{2-}, \\
\text { Molar Ratio }\end{array}$ \\
\hline Cheju $^{\mathrm{a}}$ & 8.0 & 1.5 & 1.3 & 1.4 & 0.5 & 1.1 & 0.27 & 1.6 & & & 0.40 & 0.29 \\
\hline Nara $^{\mathrm{b}}$ & 3.90 & 2.64 & 1.25 & 0.37 & 0.24 & 0.36 & 0.07 & 0.95 & & & 0.73 & 1.0 \\
\hline Shinoro $^{c}$ & 4.1 & 1.2 & 0.79 & 0.64 & 0.14 & 0.71 & 0.12 & 0.62 & 6.7 & 3.3 & 0.42 & 0.45 \\
\hline Higashi-Tsukisamu $^{\mathrm{c}}$ & 4.0 & 0.9 & 0.64 & 0.48 & 0.13 & 0.83 & 0.10 & 0.49 & 7.2 & 3.6 & 0.36 & 0.35 \\
\hline
\end{tabular}

${ }^{a}$ Average aerosol concentrations in April at Cheju Island during 1992-1995 (All values in $\mu \mathrm{g} \mathrm{m}^{-3}$ ) [Carmichael et al., 1997; Chen et al., 1997].

${ }^{\mathrm{b}}$ Average aerosol concentrations in April at Nara, Japan (All values in $\mu \mathrm{g} \mathrm{m}^{-3}$ ) [Matsumoto and Okita, 1998].

${ }^{\mathrm{c}}$ Average aerosol concentrations at Sapporo, Japan during 1998 (Ionic species concentration in $\mu \mathrm{g} \mathrm{m}^{-3}$, total carbon (TC) and elemental carbon (EC) concentrations in $\mu \mathrm{gC} \mathrm{m}^{-3}$ ) [Kaneyasu et al., 1995]. 
Table 8. Summary of AMS Measurements of Sulfate, Nitrate, Organics, and Ammonium Mass Concentrations and the Corresponding Molar and Mass Ratios at Different Altitudes

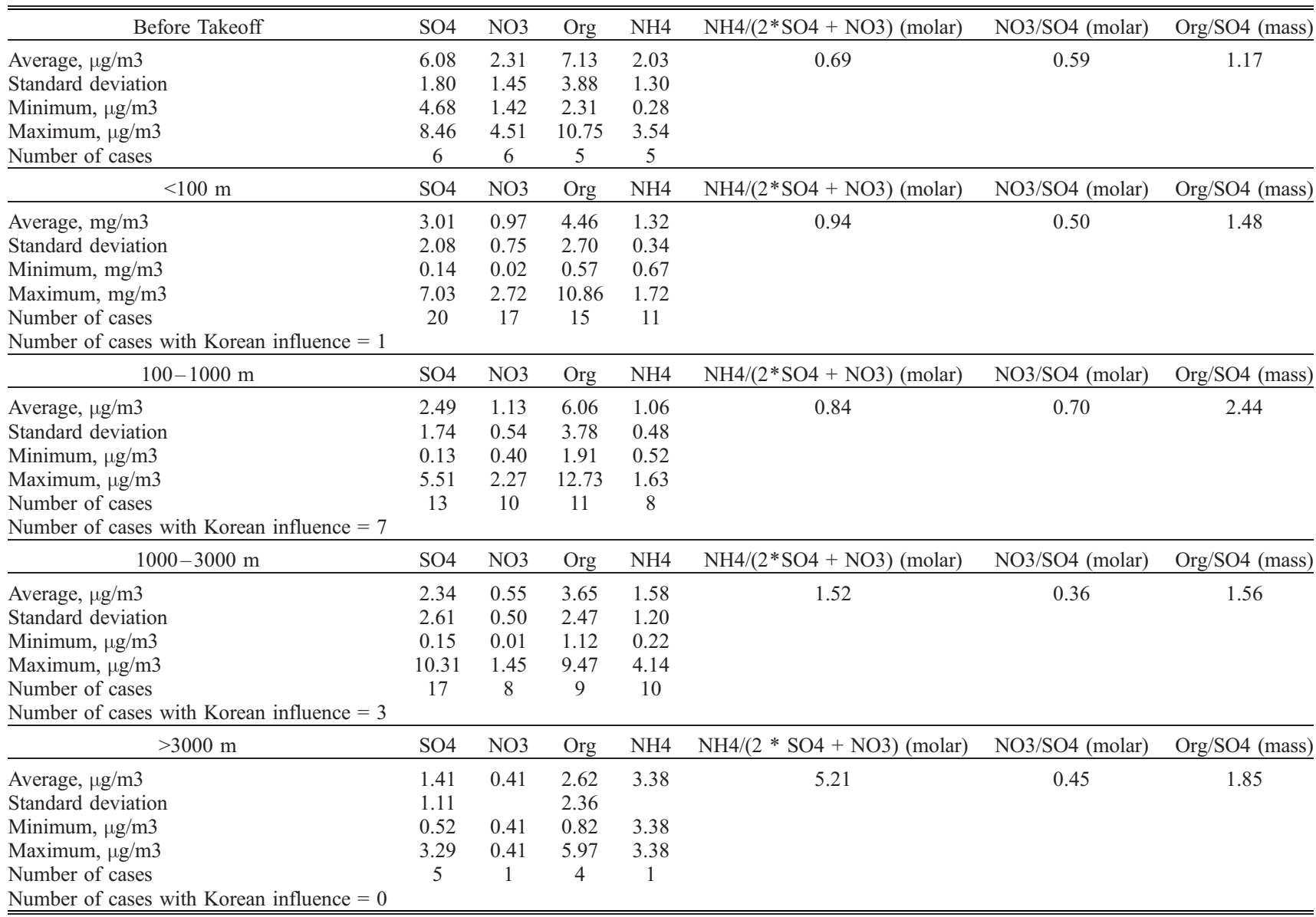

lower in summer and fall. On average, total carbonaceous aerosol contribution to the $\mathrm{PM}_{10}$ mass concentration was $\sim 32 \%$, while sulfate and nitrate contributions were $\sim 9 \%-$ $27 \%$ and $\sim 4 \%$, respectively. Sulfate concentrations measured at both sites were comparable throughout the year. Particulate nitrate and ammonium showed maximum concentrations during winter, presumably reflecting the shift of the ammonium nitrate gas-particle equilibrium toward the aerosol phase at lower temperatures. Table 7 summarizes average concentrations of sulfate, nitrate, ammonium, and organics reported by Carmichael et al. [1997], Matsumoto and Okita. [1998], and Kaneyasu et al. [1995].

[47] Back-trajectory analysis showed that air masses from eastern/northeastern China were sampled during most of the Twin Otter flights (G.R. Carmichael, University of Iowa, personal communication, 2002). There were only a few legs where air masses from Korea were sampled, during which slightly higher organic concentrations were observed. During the previous studies in the region, higher sulfate levels were observed at Cheju, Korea than at Nara and Sapporo, Japan [Carmichael et al., 1997; Chen et al., 1997; Kaneyasu et al., 1995; Matsumoto and Okita, 1998]. This is attributed to the fact that during springtime the air masses sampled at Cheju had the influence of emissions in northern and eastern China while those sampled in Japan had the influence of local urban emissions. Similarly, during the
Twin Otter flights, the AMS measured higher sulfate concentrations while sampling air masses from northern China rather than Korea. It is worth mentioning, though, that the highest sulfate concentrations were measured by the AMS on the ground at Iwakuni, Japan, before takeoff, which might be an indication of locally high sulfate precursor emissions and low dilution, compared to the air masses sampled over the ocean that had been advected away $\sim 1000-2000 \mathrm{~km}$.

[48] A summary of the AMS measurements of mass concentration and the corresponding molar and mass ratios of sulfate, nitrate, organics, and ammonium at different altitudes is presented in Table 8. At altitudes less than $1000 \mathrm{~m}$, the molar ratio of $\mathrm{NH}_{4}^{+} /\left(2 \mathrm{SO}_{4}^{2-}+\mathrm{NO}_{3}^{-}\right)$and $\mathrm{NO}_{3}^{-} / \mathrm{SO}_{4}^{2-}$ and the mass ratio of organics $/ \mathrm{SO}_{4}^{2-}$ averaged $0.9,0.6$, and 1.96, respectively. Average sulfate, nitrate, and ammonium concentrations at altitudes less than $1000 \mathrm{~m}$ measured by the AMS during Twin Otter flights are lower than ground measurements at Cheju, Korea, during April 1997 by $65 \%, 30 \%$, and $8 \%$, respectively [Carmichael et al., 1997; Chen et al., 1997]. Thus the molar ratio of $\mathrm{NH}_{4}^{+} /$ $\left(2 \mathrm{SO}_{4}^{2-}+\mathrm{NO}_{3}^{-}\right)$and $\mathrm{NO}_{3}^{-} / \mathrm{SO}_{4}^{2}$-based on the AMS measurements are higher than those measured at Cheju, Korea. Similarly, the AMS measurements during Twin Otter flights show lower concentrations for sulfate, nitrate, and ammonium by $29 \%, 60 \%$, and $5 \%$ than the concentrations 
measured at Nara, Japan [Matsumoto and Okita, 1998]. Sulfate, nitrate, and organics concentrations measured by the AMS during Twin Otter flights are 31\%, 5\%, and 7\% less than the measurements at Sapporo, Japan while the ammonium concentration is higher by $68 \%$ [Kaneyasu et al., 1995]. However, since air masses at Nara and Sapporo may be more representative of local urban emissions of Japan, it is more appropriate to compare AMS measurements on the ground, before takeoff, at Iwakuni, Japan, to the measurements at these sites. This comparison yields only $20 \%$ difference in ratios of $\mathrm{NH}_{4}^{+} /\left(2 \mathrm{SO}_{4}^{2-}+\mathrm{NO}_{3}^{-}\right)$and $\mathrm{NO}_{3}^{-} / \mathrm{SO}_{4}^{2-}$ based on AMS measurements and average values of measurements at Nara and Sapporo.

[49] Song and Carmichael [1999] employed a chemical transport model to simulate aerosol evolution over the eastern Asia region. Simulations were carried out for a two-day period with initial conditions based on observations at Cheju Island, Korea. Simulations showed that $\mathrm{SO}_{2}$ and $\mathrm{H}_{2} \mathrm{SO}_{4}$ are taken up mostly by the fine particle mode because of the larger available surface area associated with this mode. Furthermore, simulations indicated that, for seasalt aerosols, sulfate replaces the fine mode nitrate and chloride and neutralizes the cations. If particles are acidic after sulfuric acid uptake, then gas-phase ammonia is taken up for further neutralization. If aerosols are still sulfate rich, self-neutralization by $\mathrm{H}_{2} \mathrm{SO}_{4} \rightarrow \mathrm{HSO}_{4}^{-}+\mathrm{H}^{+}$ is predicted to become dominant. However, sulfate deposition onto coarse mode sea-salt aerosols is slower, because of their smaller available surface area, and sulfate preferentially replaces the higher volatility chloride rather than nitrate. At the end of the second day, the model predicts a species molar ratio of $\mathrm{NH}_{4}^{+} / \mathrm{SO}_{4}^{2-}=1.12$ for the fine mode [Song and Carmichael, 1999]. One would expect the $\mathrm{NH}_{4}^{+} / \mathrm{SO}_{4}^{2-}$ ratio based on the simulations to be different than that based on AMS measurements since the initial conditions of the model are based on observed concentrations at Cheju, Korea, which on most days are different from those measured by the AMS. However, the qualitative picture of sulfate dominated and partially neutralized submicron aerosols is consistent with AMS measurements. Considering only those legs of Twin Otter flights which had influence of Korean emissions, the molar ratio of $\mathrm{NH}_{4}^{+} / \mathrm{SO}_{4}^{2-}$ was estimated to be 1.9. The higher molar ratio of $\mathrm{NH}_{4}^{+} / \mathrm{SO}_{4}^{2-}$ indicates that the aerosols that were sampled by the AMS were neutralized to a greater extent than model predictions. This can be explained by longer transport of aerosols from the source regions and continuous uptake of ammonia along the way.

\section{Conclusions}

[50] An Aerodyne aerosol mass spectrometer was deployed in an aircraft for the first time during ACE-Asia. It successfully operated on 15 out of 19 research flights and provided information on size-resolved chemical composition of the nonrefractory components of the submicron Asian aerosols. Size-resolved mass concentration measurements of nonrefractory aerosols by the AMS indicate that discrete layers of pollution were present up to an altitude of $\sim 3700 \mathrm{~m}$ in the Asian aerosol outflow during the ACE-Asia field campaign. Pollution layers, marked by high concentrations of sulfate and organics, as high as $10 \mu \mathrm{g} \mathrm{m}^{-3}$ and
$13 \mu \mathrm{g} \mathrm{m}^{-3}$, respectively, were separated by cleaner layers with lower aerosol loadings. Ammonium and nitrate were also detected in some layers with concentrations up to $\sim 4$

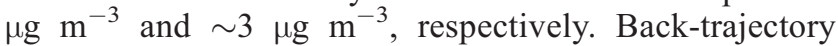
analysis showed that pollution layers that originated in Korea had somewhat higher organics contribution while pollution layers from China contained a higher fraction of sulfate aerosols. Real-time mass distribution measurements of the aerosols also indicate that sulfate and ammonium mass distributions at various altitudes were uniform during the campaign. Less than unity values of the molar ratio of positive to negative ionic charges of the nonrefractory components of the aerosols on most of the constant altitude legs of Twin Otter flights is an indication of partially neutralized aerosols in the region. On the days with less influence of dust in the aerosol outflow, the total mass of nonrefractory aerosols estimated by the AMS correlated well with the total volume of aerosols measured by a differential mobility analyzer.

[51] Acknowledgments. We thank Dean Hegg, Song Gao, Rodney Weber, Kari Maxwell, Douglas Orsini, and Barry Huebert for sharing their data for comparison purposes, as well as Greg Carmichael for providing us with back trajectories. We also thank the CIRPAS-Twin Otter flight crew for their support during the field project. This work was supported by the National Science Foundation (NSF) and the Office of Naval Research (ONR).

\section{References}

Allan, J. D., et al., Quantitative sampling using an Aerodyne aerosol mass spectrometer: 2. Measurements of fine particulate chemical composition in two UK cities, J. Geophys. Res., 108(D3), 4091, doi:10.1029/ 2002JD002359, 2003a.

Allan, J. D., J. L. Jimenez, H. Coe, K. N. Bower, P. I. Williams, and D. R. Worsnop, Quantitative sampling using an Aerodyne aerosol mass spectrometer: 1. Techniques of data interpretation and error analysis, J. Geophys. Res., 108(D3), 4090, doi:10.1029/2002JD002358, 2003b.

Bates, T., B. J. Huebert, J. L. Gras, F. B. Griffiths, and P. A. Durkee, International Global Atmospheric Chemistry (IGAC) project's first Aerosol Characterization Experiment (ACE 1): Overview, J. Geophys. Res., 103(D13), 16,297-16,318, 1998.

Bird, R. B., W. E. Stewart, and E. N. Lightfoot, Transport Phenomena, pp. 46, John Wiley, Hoboken, N. J., 2002.

Carmichael, G. R., M. S. Hong, H. Ueda, L. L. Chen, K. Murano, J. K. Park, H. Lee, Y. Kim, C. Kang, and S. Shim, Aerosol composition at Cheju Island, Korea, J. Geophys. Res., 102(D5), 6047-6061, 1997.

Chen, L. L., et al., Influence of continental outflow events on the aerosol composition at Cheju Islan, South Korea, J. Geophys. Res., 102(D23), 28,551-28,574, 1997 .

Drewnick, F., J. J. Schwab, J. T. Jayne, M. Canagaratna, D. R. Worsnop, and K. L. Demerjian, Measurements of ambient aerosol composition during the PMTACS-NY 2001 using an aerosol mass spectrometer, part I: Mass concentrations, Aerosol Sci. Technol., in press, 2003.

Hinds, W. C., Aerosol Technology: Properties, Behavior, and Measurements of Airborne Particles, John Wiley, Hoboken, N. J., 1999.

Jayne, J. T., D. C. Leard, X. Zhang, P. Davidovits, K. A. Smith, C. E. Kolb, and D. Worsnop, Development of and aerosol mass spectrometer for size and composition analysis of submicron particles, Aerosol Sci. Technol., 33, 49-70, 2000

Jimenez, J. L., R. Bahreini, D. R. Cocker III, H. Zhuang, V. Varutbangkul, R. C. Flagan, J. H. Seinfeld, C. D. O'Dowd, and T. Hoffmann, New particle formation from photooxidation of diiodomethane $\left(\mathrm{CH}_{2} \mathrm{I}_{2}\right)$, J. Geophys. Res., 108(D10), 4318, doi:10.1029/2002JD002452, 2003a.

Jimenez, J. L., et al., Ambient aerosol sampling using the Aerodyne Aerosol Mass Spectrometer, J. Geophys. Res., 108(D7), 8425, doi:10.1029/ 2001JD001213, 2003b.

Kaneyasu, N., S. Ohta, and N. Murao, Seasonal variation in the chemical composition of atmospheric aerosols and gaseous species in Sapporo, Japan, Atmos. Environ., 29(13), 1559-1568, 1995.

Liu, P., P. L. Ziemann, D. B. Kittelson, and P. H. McMurry, Generating particle beams of controlled dimensions and divergence: I. Theory of particle motion in aerodynamic lenses and nozzle expansion, Aerosol Sci. Technol., 22, 293-313, 1995a. 
Liu, P., P. L. Ziemann, D. B. Kittelson, and P. H. McMurry, Generating particle beams of controlled dimensions and divergence: II. Experimental evaluation of particle motion in aerodynamic lenses and nozzle expansions, Aerosol Sci. Technol., 22, 314-324, 1995b.

Matsumoto, M., and T. Okita, Long term measurements of atmospheric gaseous and aerosol species using an annular denuder system in Nara, Japan, Atmos. Environ., 32(8), 1419-1425, 1998.

McKeown, P. J., M. V. Johnston, and D. M. Murphy, Online single-particle analysis by laser desorption mass-spectrometry, Anal. Chem., 63(18), 2069-2073, 1991.

McLafferty, F. W., and F. Turecek, Interpretation of Mass Spectra, Univ. Sci. Books, Sausalito, Calif., 1993.

Raes, F., T. Bates, F. McGovern, and M. C. Liedekerke, The 2nd Aerosol Characterization Experiment (ACE-2), General overview and main results, Tellus, Ser. B, 52, 111-125, 2000.

Schmid, B., et al., Column closure studies of lower tropospheric aerosol and water vapor during ACE-Asia using airborne sunphotometer, airborne insitu and ship-based lidar measurements, J. Geophys. Res., 108(D23), 8656, doi:10.1029/2002JD003361, in press, 2003.

Seinfeld, J. H., and S. N. Pandis, Atmospheric Chemistry and Physics: From Air Pollution to Climate Change, John Wiley, Hoboken, N. J., 1998.

Song, C. H., and G. R. Carmichael, The aging process of naturally emitted aerosol (sea-salt and mineral aerosol) during long range transport, Atmos. Environ., 33, 2203-2218, 1999.

Suess, D. T., and K. A. Prather, Mass spectrometry of aerosols, Chem. Rev, 99, 3007-3035, 1999.
Wang, J., et al., Clear-column radiative closure during ACE-Asia: Comparison of multiwavelength extinction derived from particle size and composition with results from Sun photometry, J. Geophys. Res., 107(D23), 4688, doi:10.1029/2002JD002465, 2002.

Willeke, K., and P. A. Baron, Aerosol Measurement: Principles, Techniques, and Applications, Van Nostrand Reinhold, New York, 1993.

Zhang, X., K. A. Smith, D. R. Worsnop, J. L. Jimenez, J. T. Jayne, and C. E. Kolb, A numerical characterization of particle beam collimation by an aerodynamic lens-nozzle system: part I. An individual lens or nozzle, Aerosol Sci. Technol., 36, 617-631, 2002.

R. Bahreini, California Institute of Technology, 1220 E. California Blvd., Department of Environmental Science and Engineering, MC 138-78, Pasadena, CA 91125, USA. (broya@caltech.edu)

R. C. Flagan and J. H. Seinfeld, California Institute of Technology, 1200 E. California Blvd., Department of Chemical Engineering, MC 210-41, Pasadena, CA 91125, USA. (flagan@cheme.caltech.edu; seinfeld@ caltech.edu)

J. T. Jayne and D. R. Worsnop, Aerodyne Research Inc., 45 Manning Rd., Billerica, MA 01821, USA. (jayne@aerodyne.com; worsnop@aerodyne. com)

J. L. Jimenez, University of Colorado at Boulder, Department of Chemistry and Biochemistry, CIRES, UCB 216, Boulder, CO 80309, USA. (jose.jimenez@colorado.edu)

J. Wang, Brookhaven National Laboratory, 75 Rutherford Drive, Environmental Science Department, Upton, NY 11973, USA. (jian@bnl.gov) 